\title{
The rise and fall of scary numbers: The effect of perceived trends on future estimates, severity ratings, and help-allocations in a cancer context
}

Arvid Erlandsson, Sigrid Moyner Hohle, Erik Lohre and Daniel Västfjäll

The self-archived postprint version of this journal article is available at Linköping University Institutional Repository (DiVA):

http:// urn.kb.se/ resolve?urn=urn:nbn:se:liu:diva-153704

N.B.: When citing this work, cite the original publication.

Erlandsson, A., Hohle, S. M., Lohre, E., Västfäll, D., (2018), The rise and fall of scary numbers: The effect of perceived trends on future estimates, severity ratings, and help-allocations in a cancer context, J ournal of Applied Social Psychology, 48(11), 618-633. https:// doi.org/ 10.1111/jasp.12552

Original publication available at:

https:// doi.org/ 10.1111/jasp.12552

Copyright: Wiley (12 months)

http:// eu.wiley.com/WileyCDA/ 
NOTE: This is a preprint of the published article:

Erlandsson, A., Hohle, S. M., Løhre, E., \& Västfjäll, D. (2018). The rise and fall of scary numbers: The effect of perceived trends on future estimates, severity ratings, and help-allocations in a cancer context. Journal of Applied Social Psychology, 48(11), 618-633. doi:doi:10.1111/jasp.12552

The rise and fall of scary numbers: The effect of perceived trends on future estimates, severity ratings and help-allocations in a cancer context.

(Word count 10874 including abstract and reference list)

\begin{abstract}
Statistical information such as death risk estimates is frequently used for illustrating the magnitude of a problem. Such mortality statistics are however easier to evaluate if presented next to an earlier estimate, as the two data points together will illustrate an upward or downward change. How are people influenced by such changes? In seven experiments, participants read mortality statistics (e.g., number of yearly deaths or expert-estimated death risks) made at two points of time about various cancer types. Each cancer type was manipulated to have either a downward trajectory (e.g., the estimated death risk was 37\% in 2012, and was adjusted downwards to $22 \%$ in 2014), an upward trajectory (e.g. $7 \% \rightarrow 22 \%$ ) or a flat trajectory (e.g. $22 \% \rightarrow 22 \%$ ). For each cancer type, participants estimated future mortality statistics and rated the perceived severity. They also allocated real money between projects aimed at preventing the different cancer types. Participants' responses indicated that they thought that a trend made out of two data points would continue in the future. People also perceived cancer types with similar present mortality statistics as more severe and allocated more money to them when they had an upward trajectory compared to a flat or downward trajectory. Although there are boundary conditions, we conclude that people's severity ratings and helping behavior can be influenced by trend information even when such information is based on only two data points.
\end{abstract}

Keywords: Trend effect; Helping allocations; Cancer statistics; Perceived severity; Forecasts; Mortality numbers; Downward/Upward trajectories 
Numbers and statistics are often used when describing and communicating problems and existing needs. For example, there are 22.5 million refugees in the world ${ }^{1}$, the estimated number of new cancer cases in the USA in 2017 is 1,688,780 ${ }^{2}$, and New York City will be flooded up to 17 times more frequently over the next century. ${ }^{3}$ A question of utmost importance is how numbers like this influence people's thoughts, feelings and behavior. More specifically, when do numbers and statistical information make us perceive a problem as more or less severe, and what kind of numerical information make us more motivated to allocate resources to a specific charitable cause?

\section{Mortality numbers and helping}

Much research discusses how numbers and statistical information about e.g. dead people influence helping. On the one hand, several lines of research predict that high numbers of dead or needy people are generally discouraging, and that people will be the most motivated to help when there is a single identified individual in need and when it is possible to help that individual (Kogut \& Ritov, 2011; Small, Loewenstein \& Slovic; Bartels, 2006; Mata, 2016; Västfjäll et al., 2014; Slovic, 2007; Västfjäll, Slovic \& Mayorga, 2015). On the other hand, other lines of research suggest that including statistical information and numbers in charity appeals sometimes can increase prosocial behavior (Bachke, Alfnes \& Wik, 2017; Cryder, Loewenstein \& Scheines, 2013; Erlandsson et al., 2016; Kleber et al., 2013; Lesner \& Rasmussen, 2014).

Importantly, mortality numbers are often difficult to interpret when they are presented in isolation, but easier to interpret when they are presented next to something comparable (Hsee \& Zhang, 2010; Peters et al. 2009). For example, the number of people dying from breast cancer in the UK in 2011 was 10,395. Presented alone, this number does not tell us much, but presented with additional information (e.g., the total number of deaths in the UK during the same period was 484,367 ) it becomes easier to evaluate and react to. Arguably, numbers seem to be much more evaluable and hence have the potential of influencing us more when they can be compared with other numbers, than when they are presented in isolation.

\section{Perceived trends}

One of the ways in which numbers can become more meaningful is when they are used to illustrate changes over time. For example, the number of people dying from HIV-related causes 
in the African Region decreased from around 1.2 million in 2009 to 790,000 in 2014. Now imagine another (hypothetical) Disease X that killed 400,000 people in 2009, and 790,000 people in 2014. In the first example (HIV), the number of deaths in 2014 (790,000) arguably conveys a somehow positive message as it represents a substantial decrease in the number of deaths compared to five years earlier. In the second example (Disease X), the same number of deaths clearly conveys a negative message as it represents an increase of something undesirable.

Recent studies by Hohle and Teigen $(2015 ; 2018)$ demonstrated that changes over time may indeed make numbers become more influential. Participants in their studies read expert forecasts made at two points in time about various events (e.g. effects of climate change and environmental risks). The forecasts had been adjusted either upwards or downwards (e.g. the expected rise of the sea level was $60 \mathrm{~cm}[20 \mathrm{~cm}]$ in the forecast made in 2000 , but $40 \mathrm{~cm}$ in the forecast made in 2010) and participants were asked to estimate what they thought the next forecast of sea level rise would be. Hohle and Teigen proposed three possible strategies that a participant could adopt: (1) sticking with the latest forecast, (2) estimating that the next forecast would lie somewhere in between the two previous forecasts, or (3) estimating that the next forecast would continue on the perceived trend. Over several experiments, participants provided estimates that supported continued trends. Forecasts that had been adjusted downwards once were assumed to become even lower in the future, whereas forecasts adjusted upwards once were assumed to become even higher in the future. This phenomenon was referred to as the trend effect. A similar effect was independently demonstrated by Maglio and Polman (2016), who found that event probabilities that have been revised upwards (e.g., from $20 \%$ to $30 \%$ ) make the event feel closer and more likely to occur than probabilities that have been revised downwards (e.g., from $40 \%$ to $30 \%$ ).

The trend effect has been found for probabilities, quantity predictions and rankings that are subject to revision. In a study by Pettit et al. (2013), equally ranked persons and products were perceived as having higher status if their ranking had been adjusted upwards (this brand was ranked sixth two years ago and is now ranked fourth) than if it had been adjusted downwards (ranked second two years ago and ranked fourth now), and this also influenced willingness to pay for the product. Numbers are not necessary for creating perceived trends. Hohle and Teigen (2015) used a "traffic-light scale" (Bostrom, Anselin \& Farris, 2008) and showed that a yellow 
(medium) risk is interpreted much differently when it is preceded by green (thus indicating a worsening state of affairs) than when it is preceded by red (thus indicating an improving state of affairs).

There are several possible reasons to why revised estimates are interpreted as trends that will continue into the future. Shen and Hsee (2017) argue that an increasing meaningless number can nudge people to perform better (e.g. walking faster on a step machine). However, it only improves performance when the increase of the meaningless number is accelerating, and even impair performance when the increasing number is deaccelerating. Maglio and Polman (2016) explain the trend effect with psychological momentum theory, meaning that people believe that physical as well as psychological objects in motion will continue along the current path (Hubbard, 2014; Markman \& Guenther, 2007). When presented with a revised estimate, people may perceive a momentum and therefore expect further changes in the same direction. The direction of change may also provide people with a gist of the statistical information (Reyna 2004; Reyna and Brainerd 1995) upon which they base their guesses about the future and severity judgment. Since the mortality statistics itself may be hard to evaluate, the direction in which it changes (up or down) may provide a quick way to judge whether there is reason for concern (and help is needed) or relief (it goes in the right direction without my help). Alternatively, Hohle and Teigen $(2015,2018)$ propose that people's general pattern-seeking tendency makes it easy to construe an upward or downward change as a trend, and extrapolate this trend to the future. Recent studies have showed that trend continuation persists when the two different forecasts are done by different experts, and it also persists when people process the forecast more deliberately by writing possible reasons for the revisions (Hohle \& Teigen, 2018). These findings suggest that the trend effect cannot be understood as a mindless extension of a number sequence, but rather that it arise from relatively analytical processes (Kahneman, 2003).

Importantly, expecting further changes in the same direction is a highly useful heuristic in some contexts, such as when there is a large number of observations, and when a known mechanism underlying the change is expected to remain operative. For example, the number of global land-surface air-temperature anomalies from 1880 to 2009 include many points of measure that together create an increasing trend (Lewandowsky, 2011). In this case, it is a functional heuristic to assume that the perceived trend will continue and that the number of 
anomalies will keep rising. However, it is arguably less functional to predict a continued trend when there are only two points of measure, and especially when the points illustrate updated forecasts (e.g., the expected number of air-temperature anomalies as rated by an expert at two points in time) rather than observations (e.g., the number of air-temperature anomalies for the past years).

\section{The current study}

This study builds on and extends the trend effect findings presented by Hohle and Teigen $(2015 ; 2018)$. Whereas those studies focused on how updated forecasts about environmental risks influence people's future estimates, this study takes place in the context of mortality statistics for various cancer-types, with a focus primarily on how trends influence perceptions of threat (e.g. "how severe do you think this disease is?") and actual allocation decisions (e.g. "do you want to allocate money for preventing this disease instead of another disease?"). We test whether cancer types for which deaths and death risks have increased are perceived as more severe and receive more (or less) donations, compared to cancer types with decreasing deaths and death risk. This study thus connects theoretical research on the trend effect with applied research on charitable decision-making and nonprofit marketing. We conducted seven experiments and include all of them to maximize transparency and reproducibility. To increase readability, four studies are reported in detail in this paper whereas three are summarized in the paper and reported in detail in Appendix 2. To provide busy readers with a graphical summary of the obtained results we also briefly present the results from a single-paper meta-analysis including all seven studies (McShane \& Böckenholt, 2017).

In Studies 1 and 2, we manipulate the trajectories of the number of deaths as a result of four different cancer types. For each cancer type, the number of deaths in 2013 is always the same but the number of deaths at the previous point of measure (2011) is manipulated to create either an upward (e.g., 177 died from this cancer in 2011 and 196 died from it in 2013), downward (e.g., 215 died from it in 2011 and 196 died in 2013) or flat trajectory (e.g., 196 died in 2011 as well as in 2013). In Studies 3 and 4, the revised numbers illustrate expert-estimated death risk forecasts rather than number of deaths.

For studies involving both observed numbers of deaths and death risk forecasts, we expect that: (1) People will guess that the trajectories continue at the next point of measure - thus 
conceptually replicating findings from Hohle and Teigen (2015) and Maglio and Polman (2016). (2) Cancer types with upward trajectories will be perceived as more severe than cancer types with downward trajectories, as past research has shown that people often use the number of deaths as a proxy of severity (Evangelidis \& van den Bergh, 2013). When it comes to allocation decisions we have two competing hypotheses: (3a) that people will allocate more money to cancer types with upward trajectories as they seem to cause more deaths, and the number of deaths have been shown to predict helping responses (Kleber et al., 2013; Evangelidis \& van den Bergh, 2013) or (3b) that people will allocate more money to cancer types with downward trajectories because people anticipate more positive emotions and prefer to help charitable causes that convey efficacy and are relatively closer to the desired end (i.e. the goal-gradient effect; Cryder, Loewenstein \& Seltman, 2013).

We are aware of only a few studies that tested how two-time based trends influence actual behavior. Participants in Study 10 in Maglio and Polman (2016) were slightly more likely to choose a wine bottle at risk of cork contamination when the risk had been adjusted downwards (from $20 \%$ to $15 \%$ ) compared to upwards (from $10 \%$ to $15 \%$ ). More recently, Mortensen et al (2018) found that participants who read that minority norms were trending upwards (e.g. 17\% of you donated money two years ago, but $48 \%$ of you did so this year) agreed to volunteer more than those who only read the minority norm (e.g. $48 \%$ of you donated money this year). In the current study, we test how perceived trends influence allocation decisions in helping dilemmas (Erlandsson, Björklund \& Bäckström, 2017; Fetherstonhaugh et al., 1997) meaning that participants are asked to choose which of the presented cancer types they prefer to prevent and cure. Allocation decisions are not the same as traditional donation decisions (i.e. should I donate money or should I keep the money for myself?), but takes place every day when philanthropists, policy makers and individuals ponder which of thousands of charitable causes that most deserves their help. To our knowledge, no previous studies have tested how the trend effect influences any type of helping behavior.

To summarize, two distinctions can be used for illustrating how the current study differs from other studies on this topic. First, the number of past data points. Most studies on how people extrapolate trends include a series of multiple data points prior to participants making their prediction (Harvey \& Bolger, 1996; Harvey \& Reimers, 2013; Lewandowsky, 2011). In the 


\section{THE TREND EFFECT ON SEVERITY AND HELP-ALLOCATIONS}

current study (as in Hohle \& Teigen, 2015, and Maglio \& Polman, 2016), participants base their estimation on only two previous data points illustrating either observations (e.g. number of deaths caused by Cancer type X during each of the past two years; Studies $1 \& 2$ ) or updated forecasts (e.g. estimated death risk for those with Cancer type $\mathrm{X}$ during each of the past two years; Studies 3-4). Second, rather than simply assessing participants' future estimates (e.g., how many do you think will die from Disease $\mathrm{X}$ next year?), we are primarily interested in the psychological and behavioral consequences of different trajectories. We therefore measure perceived severity of the cancer-types (all studies) and donation allocations (Studies 2-4). 


\section{Study 1}

The aim of Study 1 was first, to replicate the trend effect in a cancer context, and second, to investigate if perceived trajectories based on two points of measure influence not only future estimates but also perceived severity of different types of cancer.

To test these predictions, we presented participants with mortality statistics of four rare types of cancer for the years 2011 and 2013, and asked them to estimate the number of deaths that had occurred in 2015 (the data was collected in February 2016). For each cancer type, participants saw either statistics with an upward trajectory (the number of deaths in 2013 was higher than in 2011), statistics with a downward trajectory (the number of deaths in 2013 was lower than in 2011), or statistics with a flat trajectory (the number of deaths in 2011 and 2013 was identical). Importantly, all participants read at least one cancer type with each type of trajectory. Four rather than three cancer-types were shown in order to make the three trajectorytypes a little less salient (including one trajectory of each type would make it very easy to see what we aimed to test).

\section{Method}

\section{Participants}

We originally distributed 160 questionnaires to people at a Swedish university campus. Seven questionnaires that were either not returned or where the participants had not followed instructions (i.e. skipped more than $50 \%$ of the questions or repeatedly communicated with others during participation) were excluded prior to any analyses (this exclusion criteria was used in all studies). In order to keep the design perfectly balanced, we replaced these with an additional seven questionnaires. The final sample included 85 female, 73 male and 2 unclassifiable participants $\left(M_{\mathrm{age}}=23.74, S D=4.87\right)$.

\section{Procedure and Material}

Participants were approached individually and asked to complete a short pen-and-paper questionnaire. The first page always contained instructions, and participants were ensured anonymity and learned that they could withdraw from participation at any time. By completing the questionnaire, participants provided their informed consent. On the following pages, 
participants read short descriptions about four relatively rare types of cancer (Hodgkin's lymphoma, Pancreatic cancer, Gall bladder cancer and Endocrine gland tumors). Half of the participants read the cancer types in this order whereas the other half read them in the opposite order.

For each cancer type, participants read a short description of the nature of the cancer type, and then learned about the number of people who died from it in Sweden in 2011 and 2013 respectively. The number of deaths each year was conveyed both in the text and in an illustration, which included two dots linked by a line (see Figure 1 for examples and Appendix 1 for all trajectories). The number of deaths in 2013 was the same in all versions, but the number of deaths in 2011 varied so that the number of deaths per year either went up (e.g., 177 to 196), down (e.g., 215 to 196) or remained unchanged (e.g., 196 to 196). The number of deaths in 2013 varied between 196 and 204 for the different cancer types and the change in numbers of deaths between 2011 and 2013 varied from 19 to 56 (see Table 1). Each participant read about one cancer type with a flat trajectory, one or two cancer types with an upward trajectory and one or two cancer types with a downward trajectory. ${ }^{4}$ After reading about each cancer type, participants were asked to estimate the number of deaths from that cancer type in $2015 .^{5}$

---Figure 1 around here---

After estimating the number of deaths for all cancer types, participants were, on a separate page, asked to rate how severe each of the cancer types seemed to them. ${ }^{6}$ They did this by putting a cross on a Visual Analogue Scale - a 165 millimeter long line where the leftmost edge was labeled "not severe at all" and the rightmost edge was labeled "extremely severe". The distance in millimeters from the leftmost edge of the line to the cross was measured and divided by 165 to create a theoretical score ranging from 0 (not severe at all) to 1 (extremely severe). On the final page, participants provided some demographic information, including sex, age, political orientation $(-4=$ far left, $+4=$ far right), personal experience with cancer and routines of donating to organizations helping people with cancer. These variables did not relate to any of the outcome variables in any clear or consistent way in any of the studies, and are therefore deemed outside the scope of this article. ${ }^{7}$ 


\section{Results}

In order to avoid excessive influence of statistical outliers, we adjusted the scores of participants who had estimated an extremely low number or an extremely high number of deaths in 2015, so that their estimate was one over the highest non-outlier or one below the lowest nonoutlier. This procedure of adjusting (but not excluding) statistical outliers was used in all studies prior to any analyses, but the results do not change substantially if not adjusting the outliers.

\section{Estimated number of deaths in 2015}

As expected, the trajectories influenced estimates about the future. If aggregating all the cancer types, the mean estimated number of deaths in 2015 was $183.32(S D=25.61)$ for the downward trajectory versions, $197.16(S D=20.77)$ for the flat trajectory versions and 209.18 $(S D=27.88)$ for the upward trajectory versions, $F(2,314)=42.53, p<.001, \eta_{\mathrm{p}}{ }^{2}=.21$. Bonferronicorrected post-hoc comparisons showed that the mean estimated number of deaths in 2015 was higher for the upward trajectory versions than for the flat trajectory versions $(p<.001)$, which in turn was higher than the downward trajectory versions $(p<.001)$. The same pattern emerged for all separate types of cancer (see left panel of Table 1). These results conceptually replicate the trend effect. Despite being based on only two observations, people believe that trajectories will continue in the future.

\section{Perceived severity}

Also as expected, the trajectories influenced the perceived severity of the different cancer types. If aggregating all the cancer types, the mean perceived severity was $0.624(S D=0.199)$ for the downward trajectory versions, $0.646(S D=0.196)$ for the flat trajectory versions, and $0.683(S D=0.162)$ for the upward trajectory versions, $F(2,310)=7.48, p=.001, \eta_{\mathrm{p}}{ }^{2}=.05$. Perceived severity for the upward trajectory versions was higher than for the downward trajectory versions $(p<.001)$ and marginally higher than for the flat trajectory versions $(p=$ $.051)$. The downward and flat versions did not differ significantly from each other $(p=.497)$. Although not always significant, similar patterns emerged if looking at the cancer types separately (see right panel of Table 1). This shows that trajectories based on only two observation influence not only future estimates, but also severity ratings of different cancer types. 
THE TREND EFFECT ON SEVERITY AND HELP-ALLOCATIONS

---Table 1 around here--- 


\section{Study 2}

The aim of Study 2 was to replicate the results from Study 1, and to add a behavioral measure in the form of an allocation decision. Specifically, after rating the four cancer types separately, participants could indicate which of the four different cancer types they preferred to prevent the most, by allocating real money to it.

\section{Method}

\section{Participants}

We originally distributed 288 questionnaires to people recruited at various public locations in southern Sweden. Fourteen questionnaires that were either not returned or had not been filled in properly were excluded and replaced prior to any analyses in order to maintain a perfectly balanced design. The final sample included 168 female, 109 male and 11 unclassifiable participants $\left(M_{\mathrm{age}}=37.86\right.$ years, $\left.S D=20.51\right)$.

\section{Procedure and Material}

The data collection took place in August 2016. The design, material and procedure was identical to the one used in Study 1 with three exceptions. First, whereas perceived severity was rated on a separate page after reading all the cancer types in Study 1, it was rated on separate pages after each cancer type in Study 2. In other words, after reading about each cancer type, participants first estimated the number of deaths as a result of that cancer type in 2015, and then, on the same page, rated perceived severity by putting a cross on a 165 millimeter long Visual Analogue Scale.

Second, after reading and responding to all the cancer types, participants in Study 2 were, on a separate page, told that as a sign of gratitude for their participation, the experimenters would donate 20 SEK $(\approx 2.15)$ to organizations supporting cancer research (5760 SEK was later donated to the Swedish Child Cancer Fund). Participants were told that there is ongoing medical research also about rare cancer types such as the four they just read about. They were then asked which of the cancer types they preferred to allocate the money to, in order to prevent and cure. They made their choice by marking one of four boxes, where each box represented one of the 


\section{THE TREND EFFECT ON SEVERITY AND HELP-ALLOCATIONS}

cancer types. Miniatures of the four figures showing the trajectories were included on the allocation decision page.

Third, on the last page, participants were asked why they allocated money to that specific cancer type by rating the relevance of seven possible reasons, and if desired adding their own reasons. These post-choice justifications were included for exploratory reasons and are not discussed here. To conclude the questionnaire, participants stated their sex, age, donation routines to cancer organizations and their political attitudes. ${ }^{8}$

\section{Results}

Estimated number of deaths in 2015

The results from Study 1 were replicated. If aggregating all the cancer types, the mean estimated number of deaths in 2015 was $188.88(S D=27.77)$ for the downward trajectory versions, $201.27(S D=18.47)$ for the flat trajectory versions, and $219.94(S D=30.96)$ for the upward trajectory versions, $F(2,566)=109.60, p<.001, \eta_{\mathrm{p}}{ }^{2}=.28$. Bonferroni-corrected post-hoc comparisons showed that the mean estimated number of deaths in 2015 was higher for the upward trajectory versions than for the flat versions $(p<.001)$ which in turn was higher than for the downward trajectory version $(p<.001)$. The same pattern emerged if looking at the cancer types separately (see Table 2, left panel).

\section{Perceived severity}

The results from Study 1 were replicated. If aggregating all the cancer types, the main perceived severity was $0.578(S D=0.188)$ for the downward trajectory versions, $0.588(S D=$ $0.209)$ for the flat trajectory versions and $0.625(S D=0.177)$ for the upward trajectory versions, $F(2,562)=8.35, p<.001, \eta_{\mathrm{p}}{ }^{2}=.03$. The mean perceived severity for the upward version was higher than for the downward version $(p<.001)$ and the flat version $(p=.010)$. The downward and flat versions did not differ $(p=1.00)$. Although not always significant, similar patterns emerged if looking at each of the cancer types separately (see Table 2, center panel).

\section{Allocation decisions}

The perceived trajectories influenced participants' allocation behavior. Among the 283 participants who completed this task, $55.1 \%$ allocated to a cancer type with an upward trajectory, 
$25.8 \%$ to a cancer type with a downward trajectory and $19.1 \%$ to a cancer type with a flat trajectory. This was significantly different from a random distribution, $\chi^{2}(2)=37.74, p<.001 .^{9}$ Although not always significant, similar patterns emerged if looking at each of the cancer types separately (see Table 2, right panel). These results support our prediction that trajectories based on only two observations can influence not only future estimates and severity ratings but also real allocation decisions in helping situations.

\section{Mediation analysis}

For explorative purposes, we tested serial within subject mediation using the MEMORE macro suggested by Montoya and Hayes (2017; 10000 bootstrap samples). The hypothesized model presumed that type of trajectory (upward vs. downward) would influence estimated number of deaths which in turn would influence perceived severity and the allocation decision. The confidence interval for the indirect effect (i.e. trajectory-type $\rightarrow$ estimated number of deaths $\rightarrow$ perceived severity $\rightarrow$ allocation decision) did not include zero [CI95: $0.038-0.110$ ] indicating a significant mediation. That was however, also the case for the indirect effect including only estimated number of deaths [i.e. trajectory type $\rightarrow$ estimated number of deaths $\rightarrow$ allocation decision; CI95: $0.071-0.224$ ] and pairwise contrasts suggested that these two indirect effects did not differ in strength [CI95: -0.020 - 0.166]. The indirect effect including only perceived severity did not include zero when controlling for the other indirect effects [trajectory type $\rightarrow$ perceived severity $\rightarrow$ allocation decision CI95: $-0.042-0.052]$.

---Table 2 around here--- 


\section{Study 3}

The aim of Study 3 was to replicate the findings from Study 2 but controlling for two possible confounds. First, the trajectories in Study 1 and 2 were made up from observations (i.e., the number of deaths each year). Although it may be difficult to make reliable inferences about future estimates with only two previous points of measure, one could easily argue that if we had e.g. 20 points of measure and the number of deaths increased each year, it would be perfectly reasonable to guess that the number of deaths would increase also during the $21^{\text {st }}$ point of measure, as the continuous increase suggests that there is a mechanism underlying the change that one may expect to continue. It is arguably less functional to react to (perceived) trends in forecasts. The most recent forecast should be updated with all available knowledge, and the most informed choice would be to go with the latest updated forecast. To test if trajectories influence severity ratings and allocation decisions even when they are based on changes in forecasts, the numbers given to participants in Study 3 illustrated experts' estimates of death risk for each of the cancer types. Second, one could argue that the figures used in Studies 1 and 2 with lines linking the dots that could slope either upward and downward made the trajectories very salient. To test if trajectories influence severity rating and allocation decisions without connecting lines, we used bar diagrams rather than line diagrams in Study 3.

\section{Participants}

We originally distributed 320 questionnaires to people at various public locations in southern Sweden. Fourteen questionnaires that were either not returned or had not been filled in properly were excluded and replaced prior to any analyses. The final sample included 169 female, 138 male and 13 unclassifiable participants $\left(M_{\text {age }}=29.89\right.$ years, $\left.S D=13.27\right)$. The data collection took place in December 2016.

\section{Method and Material}

The design, material and procedure was very similar to the one used in Study 2, with the following differences: First, because the actual death risks of patients diagnosed with Pancreatic cancer and Gall bladder cancer are very high (and we expected that some participants were aware of this), we replaced these cancer types with Mouth cancer and Sarcoma respectively. 
Second, in Study 3, the numbers given to the participants illustrated the expected 10-year death risk (e.g. how many of 100 diagnosed patients are expected to die anytime during the coming 10 years as a direct result of the cancer). For each cancer type, participants learned the expected death risk in 2012 and in 2014 (both ostensibly estimated by experts at that time), and were asked to guess what the expected death risk would be in $2016 .{ }^{10}$ The death risk was conveyed both in the text and in an illustration. Unlike Study 2, the illustration was a bar diagram where a higher bar indicated a higher death risk (see Figure 2 for examples and Appendix 1 for all diagrams). As in the previous studies, the number in the latest forecast (2014) was always the same for each cancer type, but the number in the previous forecast (2012) varied so that the expected death risk either went up (e.g., $9 \%$ to $25 \%$ ), down (e.g., $41 \%$ to $25 \%$ ) or remained unchanged (e.g., 25\% to 25\%). The death risk in 2014 varied between $22 \%-25 \%$ for the different cancer types and the change in estimated death risk between 2012 and 2014 varied between $10 \%$ and $16 \%$ (see Table 3). As in the previous studies, each participant read about one cancer type with a flat trajectory, one or two cancer types with upward trajectories and one or two cancer types with downward trajectories (see Appendix 1).

Third, just as in Study 2, the allocation decision was made after reading and responding to each of the cancer types. For budget reasons, the endowment was only 10SEK in this study (3200 SEK was later donated to Swedish Child Cancer Fund.)

---Figure 2 around here---

\section{Results}

Estimated expected death risk 2016

The results from the previous studies were replicated. If aggregating all the cancer types, the mean estimate of expected death risk in 2016 was $19.73 \%(S D=5.41)$ for the downward trajectory versions, $23.11 \%(S D=3.20)$ for the flat trajectory versions, and $26.99 \%(S D=7.35)$ for the upward trajectory versions, $F(2,634)=126.26, p<.001, \eta_{\mathrm{p}}{ }^{2}=.29$. Bonferroni-corrected post-hoc comparisons showed that the estimated death risk for 2016 was higher for the upward 
versions than for the flat versions $(p<.001)$ which in turn was higher than the downward versions $(p<.001)$. The same pattern emerged if looking at the cancer types separately (see Table 3, left panel).

Perceived severity

Although weaker than in the previous study, the results from the previous studies were replicated. If aggregating all the cancer types, the mean perceived severity was $0.559(S D=$ $0.192)$ for the downward versions, $0.569(S D=0.199)$ for the flat versions and $0.585(S D=$ 0.194 ) for the upward versions, $F(2,612)=3.38, p=.035, \eta_{\mathrm{p}}^{2}=.01$. Bonferroni-corrected posthoc comparisons showed that perceived severity was higher for the upward versions than for the downward versions ( $p=.048$ ), but neither of them differed significantly from the flat versions (both $p>$.33) The same pattern emerged for three out of four cancer types if looking at them separately (although only significant for Hodgkin's Lymphoma; see Table 3, center panel).

\section{Allocation decisions}

The perceived trajectories influenced allocation decisions in this study as well. Among the 294 participants who completed this task, 55.2\% allocated to a cancer type with an upward trajectory, $25.0 \%$ to a cancer type with downward trajectory and $19.8 \%$ to a cancer type with a flat trajectory. This was significantly different from a random distribution, $\chi^{2}(2)=41.87, p<$ .001 . The same pattern emerged if looking at the cancer types separately (see Table 3, right panel). These results support our prediction that also trajectories about forecasts can influence actual allocation decisions.

\section{Mediation analysis}

For exploratory purposes, we again tested serial within subject mediation using the MEMORE macro (Montoya \& Hayes, 2017, 10000 iterations) The confidence interval for the indirect effect (i.e. trajectory type $\rightarrow$ estimated death risk $\rightarrow$ perceived severity $\rightarrow$ allocation decision) did not include zero [CI95: $0.056-0.134$ ] indicating a significant mediation. That was however, also the case for the indirect effect including only estimated death risk [trajectory-type $\rightarrow$ estimated death risk $\rightarrow$ allocation decision; CI95: $0.006-0.158]$. Pairwise contrasts suggested that these two indirect effects did not differ in strength [CI95: -0.112-0.087]. The indirect effect including 
THE TREND EFFECT ON SEVERITY AND HELP-ALLOCATIONS

only perceived severity was even negative when controlling for the other indirect effects [trajectory-type $\rightarrow$ perceived severity $\rightarrow$ allocation decision; $-0.096--0.019$ ].

---Table 3 around here--- 


\section{Study 4}

The aim of Study 4 was to replicate the results of Study 3 but controlling for two further possible confounds. First, we wanted to make sure the effect was not a result of the specific experimental design. Whereas all of the preceding studies had a mixed within-between subject design where participants read and responded to four cancer types and were exposed to all types of trajectories, Study 4 included only two cancer types and employed a traditional factorial $2 \times 2$ between subject design where the first cancer type (Hodgkin's lymphoma) was manipulated to have an upward or downward trajectory whereas the second cancer type (Endocrine gland tumors) always had a flat trajectory but was manipulated to have the most recent death risk estimate slightly below or slightly above that of Hodgkin's lymphoma. Second, we removed all graphical illustrations in Study 4 in order to see if perceived trends influence severity-ratings and allocation decisions also when communicated with mere text and numbers.

\section{Participants}

We distributed 600 questionnaires individually to people at various public locations in southern Sweden. Twenty-one of these were either not returned or not completed properly and therefore excluded prior to any analyses. ${ }^{11}$ The final sample included 214 male, 353 female and 12 unclassified participants $\left(M_{\text {age }}=26.73\right.$ years, $\left.S D=11.01\right)$.

\section{Method and Material}

All participants read about two cancer types - Hodgkin's Lymphoma (always presented first) and Endocrine gland tumors (always presented second). The texts describing the cancer types were very similar to the ones used in Study 3 but we removed the figures and relied only on numbers communicated in text (see Appendix 1 for example). Hodgkin's Lymphoma was manipulated to have either a downward trajectory (the expert-estimated expected death risk was $30 \%$ in 2012 but adjusted to 18\% in 2014), or an upward trajectory (6\% in 2012 but adjusted to $18 \%$ in 2014). Endocrine gland tumors always had a flat trajectory but was manipulated to have an expert-estimated expected death risk of either 17\% or 19\% (in both 2012 and 2014). After reading about each cancer type, participants guessed the expected death risk in 2016 and rated the perceived severity of the cancer type in the same way as in Study 3. 
The allocation decision were made on a separate page after reading and responding to both cancer types. Participants were told that 5 SEK would be donated to cancer research but that they could actively decide which type of cancer research they preferred to donate to. They showed their preference by marking the cancer type they wanted to donate money to prevent and cure (2915 SEK was later donated to the Swedish Cancer Fund). The dependent variable was the proportion of participants who allocated money to Hodgkin's Lymphoma. We were especially interested in the allocation decision of participants who were faced with Hodgkin's Lymphoma with an upward trajectory (i.e. $6 \% \rightarrow 18 \%$ death risk) and Endocrine gland tumors with a higher death risk in the latest forecast (i.e. $19 \% \rightarrow 19 \%$ death risk). The latter would receive more money if the latest forecast mattered more (because $19 \%$ is higher than $18 \%$ and these numbers are easily comparable) but the former would receive more money if the trajectory mattered more.

\section{Results}

As we were primarily interested in the ratings of the cancer type first presented, we here report only the death risk estimates and perceived severity for Hodgkin's Lymphoma. Ratings for endocrine glands tumors are described in detail in Appendix 3.

\section{Estimated expected death risk 2016}

The results from the previous studies were replicated. A $2 \times 2$ ANOVA showed that participants reading about Hodgkin's Lymphoma with an upward trajectory estimated its expected death risk in 2016 to be significantly higher $(21.40 \%, S D=6.54)$ than participants reading about it with a downward trajectory $(14.32 \%, S D=4.87 ; F(1,575)=217.59, p<.001$, $\left.\eta_{\mathrm{p}}{ }^{2}=.28\right)$. As would be expected with this design, the death risk for endocrine gland tumorsmanipulation did not influence ratings of Hodgkin's Lymphoma $(F[1,575]=1.45, p=.230$ for the main effect and $F[1,575]=1.81, p=.180$ for the interaction effect; see Table 4).

\section{Perceived severity}

The results from the previous studies were replicated. A $2 \times 2$ ANOVA showed that participants reading about Hodgkin's lymphoma with an upward trajectory perceived its severity to be significantly higher $(0.563, S D=0.176)$ than participants reading about it with a downward trajectory $\left(0.528, S D=0.178 ; F(1,568)=5.58, p=.018, \eta_{\mathrm{p}}{ }^{2}=.01\right)$. Neither the main effect of 
death risk for tumors in endocrine glands $(F[1,568]=0.02, p=.888)$ nor the interaction effect $(F[1,568]=0.44, p=.509)$ were significant.

\section{Allocation decisions}

Participants' allocation decisions differed significantly between the four conditions. $\chi^{2}(3)=$ 97.33, $p<.001$. In line with predictions, participants allocated more often to Hodgkin's Lymphoma when it had an upward trajectory (73.7\%) than when it had a downward trajectory $(32.7 \%)$ and importantly this was the case both when Hodgkin's Lymphoma had a lower $\left(\chi^{2}[1]\right.$ $=55.86, p<.001)$ and when it had a higher estimated death risk in the latest forecast compared to endocrine gland tumors $\left(\chi^{2}[1]=40.36, p<.001\right.$; see Table 4). Participants' allocations were however not sensitive to the endocrine glands tumors death risk-manipulation, $\chi^{2}(1)=1.21, p=$ .271 .

---Table 4 around here--- 


\section{Three additional studies}

Three additional studies (X, Y and Z) were conducted and the method and detailed results of these studies can be found in Appendix, 2 whereas the results in tabular form are presented in Tables $\mathrm{X}, \mathrm{Y}$ and $\mathrm{Z}$ below. To summarize, all three additional studies replicated the trend effect on future estimates, but two out of three additional studies failed to replicate the effect on perceived severity and there was no effect on actual helping decisions.

Studies X and Y were similar to Studies 1-3 with a few exceptions (see Appendix 2). Importantly, the one aspect distinguishing the three reported studies from Studies X and Y is that whereas the reported studies included four cancer types that had similar values on the latest observation or latest forecast (e.g., all four cancer types had an estimated death risk between $22 \%$ and $25 \%$ in 2014), the two additional studies included four cancer types that had very diverse values on the latest forecast (e.g., Pancreatic cancer had an estimated 94\% death risk whereas Endocrine gland tumors had an estimated 7\% death risk in 2013 in Study Y). As expected, the magnitude of the risk in the latest forecast greatly influenced severity ratings and donation decisions. Cancer types with a high death risk (or a low chance of survival) were rated as much more severe, and obtained more allocations than cancer types with lower death risk/high chance of survival. We argue that the large effect of the latest risk magnitude overshadowed the much smaller effect of the trajectory versions. In sum, the trend effect seems to have downstream consequences on severity ratings and allocation decisions as long as the alternatives are sufficiently similar on other dimensions, but not necessarily when the alternatives can be evaluated jointly and differ much on another important dimension.

Study $\mathrm{Z}$ tested the effect with a pure between-subject design, meaning that participants read about a single cancer type (Hodgkin's lymphoma) with either an upward or downward trajectory in expert-estimated death risk forecasts. This study replicated the trend effect both for future estimates and for perceived severity. Participants being presented with an upward trajectory in death risk forecasts predicted a higher expected death risk at the next forecast, and perceived the cancer type to be more severe, compared to participants being presented with a downward trajectory. Against expectations however, trajectories did not influence allocation decisions. Participants could choose between earmarking 5 SEK to prevent specifically Hodgkin's lymphoma or to donate it to cancer research in general, but this dependent variable 


\section{THE TREND EFFECT ON SEVERITY AND HELP-ALLOCATIONS}

proved to be insensitive not only to the trajectory manipulation but also to an independent death risk manipulation (the expected death risk at the latest forecast was either low [18\%] or high [51\%]). As predicted, this manipulation strongly predicted future estimates and perceived severity but against expectations, it did not influence allocation decisions at all. This suggests that this allocation decision (where one alternative was framed very generically) is different from an allocation decision where both alternatives are framed concretely (as in Studies 2-4).

Together, these additional studies show that there exist important boundary conditions in how the trend effect influence perceived severity and allocation decisions.

---Table X around here---

---Table Y around here---

---Table Z around here--- 


\section{Single-paper meta-analysis}

To provide a graphical summary of the results obtained in the seven studies we conducted three (one for each outcome variable) single-paper meta-analyses as suggested by McShane and Böckenholt (2017), and argued to be equivalent to the gold-standard meta-analytic approach. Further information about how these meta-analyses were conducted can be found in Appendix 4.

The result from the single paper meta-analysis (SPM) for mortality statistics is presented in Figure 3. The three graphs illustrate the three different contrasts; (1) downward vs. upward, (2) downward vs. flat and (3) flat vs. upward trajectory. As the different cancer-types differed a lot on mortality-statistics in Study X and Y we present the cancer-types separately and we also divided Study $\mathrm{Z}$ into two studies based on the high/low death risk manipulation.

---Figure 3 around here---

The results from the SPM for perceived severity are presented in Figure 4. To ease comparison, we present the results in the same way as done for the mortality statistics. As the outcome variable in Study X was survival chance rather than death risk (as in all other studies) we have inverted severity ratings for the downward and upward trajectories in this study.

---Figure 4 around here---

The results from the SPM for allocation decision are presented in Figure 5. Only the contrast between downward and upward trajectories is included here and the compared values were not means but proportion of participants allocating to each type of trajectory.

---Figure 5 around here--- 


\section{General Discussion}

The current studies show that two data points that together create an upward or downward trajectory can influence not only future estimates, but also perceived severity and actual allocation decisions. Cancer types where the number of yearly deaths increased from Time 1 to Time 2 were perceived as more severe (Studies 1 and 2) and were allocated more money (Study 2) than cancer types where the number of yearly deaths decreased from Time 1 to Time 2, despite the number of yearly deaths at Time 2 being identical. In Study 3, a cancer type with an expert-estimated death risk of e.g. $25 \%$ was seen as more severe and was allocated more money if the forecast had been adjusted upwards than if it had been adjusted downwards. In Study 4, we replicated this effect with a different design and without any graphical illustration, and further showed that people allocated more money to a cancer type with an upward trajectory in expected death risk than to a cancer type with a flat trajectory even when the latter had a higher death risk at the latest forecast.

The current results conceptually replicate trend effect findings by Hohle and Teigen (2015, 2018) and Maglio and Polman (2016), in that people tend to expect that a trajectory made out of only two data points will continue in the future in a context where the numbers represent mortality statistics from different cancer types. When faced with two past observations or with two expert-estimated forecasts people tend to extrapolate the perceived linear trend and estimate that the number of deaths, or the expected death risk, will continue to increase (if the two data points create an upward trajectory) or decrease (if they create a downward trajectory). This trend effect seems robust as it was found in all seven conducted studies. We interpret this finding as indicating a form of prediction bias. When predicting e.g. what the next observed number of deaths will be based on two previous observations, it is arguably more sensible to predict a number somewhere between the two past observations, or to assume that the most recent number is the most likely one (by being most up to date) unless there are reasons to believe an underlying, ongoing causal process to be at work. When predicting the next expert-estimated forecast, the informed choice is typically to opt for the most recently updated forecast, even if it is preceded by multiple forecasts that together make up an increasing or decreasing trend.

Importantly, we also find psychological consequences (perceived severity) and behavioral consequences (allocation decisions) as a function of the trajectories in Studies 1-4. This is a 
novel and potentially important finding because it means that the trend effect can influence not only how we think about different problems, but also how we feel and behave when faced with them. Creating a bridge between two fields of research, this also makes the trend effect highly relevant for researchers on charitable giving and fundraising. Specifically, people reading about a cancer type with an increase in mortality statistics perceive it to be slightly more severe than people reading about the same cancer type, when it has a decrease in mortality statistics (even if it is equally, or more, deadly at the last point of measure). Also, people allocate more resources to cancer types with increasing mortality statistics and less resources to cancer types with unchanging or decreasing mortality statistics. One explanation for this is the "dead people effect" found by Evangelidis and van den Bergh (2013), which suggests that the number of people who have died (but perversely not the number of people in need) predict how much people donate to a disaster. Participants reading about four equally lethal (at the last point of measure) cancer types seemed to expect that the cancer type with an upward trajectory would cause more deaths in the future than a cancer type with a downward trajectory, and our exploratory mediation analyses in Studies 2-3 tentatively suggest that the effect of trajectory type on allocation decision could be explained by estimated future deaths (both independently and serially) and severity ratings (only serially).

This explanation seems even more plausible considering that the downstream consequences on perceived severity and helping behavior disappeared when the four presented cancer types differed on how high the estimated death risk was in the last forecast (see additional Studies $\mathrm{X}$ and $\mathrm{Y}$ in Appendix 2). Although people still expected continued trends in these studies, they did clearly not perceive a cancer type with a low but increasing trend in death risk (e.g. $0 \%$ at Time $1 \rightarrow 7 \%$ at Time 2 ) to be as severe as a cancer type with a high but decreasing trend (e.g. $100 \%$ at Time $1 \rightarrow 94 \%$ at Time 2). They did, however, perceive a cancer type with an expected $6 \%$ death risk at Time $1 \rightarrow 18 \%$ at Time 2 to be more severe and more deserving of donations than a cancer type with a stable 19\% death risk at both times (Study 4). Taken together, it seems likely that people first and foremost base their evaluations and decisions on the latest forecast (or observation) as this is the best proxy for predicting future mortality rates. However, when the latest point of mortality statistic is sufficiently similar among the alternatives, people seek information in trends even when they are based on only two data points 
and illustrate updated forecasts, thus influencing severity ratings and helping behavior in predictable ways.

\section{Negative and positive charity appeals}

Arguably, the upward trajectory in contexts like these, where a higher number indicates something negative, can be seen as an attempt to motivate a potential donor by emphasizing the negative aspects and inducing fear and distress. In other words, a negative charity appeal focuses on the negative consequences that will occur if you do not help. In contrast, a downward trajectory in this context can be seen as an attempt to motivate a potential donor by emphasizing the positive aspects and inducing positive emotions, efficacy (e.g., things are going in the right direction; Cryder et al., 2013) and hopefulness. This kind of positive charity appeal focuses on the positive consequences that will occur if you help.

It is an ongoing debate whether charity appeals should be framed negatively (highlighting the dreadful consequences if people ignore the cause; e.g. Chou \& Murnighan, 2013) or positively (highlighting the favorable consequences if people support the cause; e.g. Das, Kerkhof \& Kuiper, 2008) or include a mix of both negative and positive messages. The results from this study tentatively support the notion that negatively framed charity appeals are better for eliciting allocations than positively framed appeals. Caution is warranted however, as a recent study suggests that although negative appeals might elicit as good or even greater actual donations in a one-shot helping decision, they are also less liked and elicit more irritation toward the organization compared to positive appeals (Erlandsson, Nilsson \& Västfjäll, 2018).

Relatedly, it should be noted that in all but one study, a higher number always indicated something negative (deaths or death risks), meaning that an upward trajectory was "indisputably bad news" and a downward trajectory "somehow good news". Importantly, this design does not make it perfectly clear to what extent the differences in responses are a consequence of the pattern of the trajectories (upward/downward) or a consequence of the meaning of the numbers making up the trajectories (here: number of deaths or death risk). In additional Study X, we switched the meaning of the numbers so that an upward trajectory indicated something positive (increasing chance of survival). Although we did not find the downstream effect on perceived severity in this study, we attribute this primarily to other aspects (discussed above). The current studies are insufficient to draw any firm conclusions, but based on past studies we expect that the 
effect of trajectories are dependent on the meaning of the underlying numbers (e.g. Davidai \& Gilovich, 2016).

\section{Limitations and future directions}

Admittedly, the results are not perfectly clear-cut. The trajectory-manipulations influenced severity-ratings and allocation decisions in many but not all studies. To a certain degree, this is a consequence of our explicit aim to be transparent and avoid the file-drawer effect. This manuscript includes all conducted studies we did on this topic, and although not all results point in the same direction we believe that we have presented reasonable explanations for all the discrepancies. We also note that whereas the trend effect on future estimates was robust and reasonably large, it was very small for perceived severity, highlighting the concern that statistically significant results not always are practically important (Freedman et al., 2007). To some extent the weak effect on severity ratings could be a result of the visual analogue scale it was measured on, but it could also be the case that severity ratings simply are not as influenced by trajectories. Interestingly, a relatively strong trend effect reemerged in the allocation decisions, and participants allocated money much more often to cancer types with upward trajectories. This finding could be linked to the prominence effect (i.e. Slovic, 1975; Tversky, Sattah \& Slovic, 1988), which refers to the phenomena that some preferences are manifested only when people have to choose between alternatives.

One could argue that even though we only had two points of measure, the difference between these points at Time 1 and 2 was at times rather big, thus indicating an underlying mechanism responsible for the change. Still, we did not see any clear patterns that greater changes elicited greater effects in our studies. Likewise, Maglio and Polman (2016) and Hohle and Teigen (2018) suggest that it is the direction rather than the magnitude of the change that influence people's perception. We also asked participants to estimate mortality statistics about the unknown past (e.g. how many do you think died last year?) rather than about the future (how many do you think will die next year?). Further studies could test to what extent these aspects influence the trend effect.

Finally, this study has not taken individual differences into account. Plenty of research suggests that different people react differently both to numerical information and to helping situations. One potentially relevant dimension where people differ is numeracy - people's ability 
to interpret and derive meaning out of numbers and statistical information (Peters et al., 2006). It has been found that people with low numeracy donate more money when the number of people in need is great, whereas people with high numeracy tend to focus more on the proportional amount of good they can make and thus donate more to small scale projects (Kleber et al., 2013; see also Dickert et al., 2011). On the one hand, trajectories (just as proportional amounts) are based on the relation between two numbers rather than on a single number and thus more demanding to compute, and this could make the trend effect stronger for highly numerate people. On the other hand, related to the issue about the inclusion of graphical illustrations vs. only numerical information, less numerate people might focus primarily on the illustration of the trajectory whereas the highly numerate might base their decision to a greater extent on the actual numbers. Our speculation would thus be that less numerate people will show a stronger trend effect when trajectories are illustrated in figures whereas high numerates will show a stronger trend effect when the trajectories are presented in tabular form.

\section{Conclusion}

The trend effect (Hohle \& Teigen, 2015, 2018) predicts that people who learn about two observations or forecasts will estimate that the next observation (or forecast) will continue on the perceived upward or downward trend. This study tested the trend effect in the realm of mortality statistics for different cancer types, and found further support for the trend effect, and importantly also psychological and behavioral downstream consequences.

Psychologically, we found that people believed that a cancer type that caused 200 deaths last year was more severe if it in the preceding year caused 180 deaths (creating an upward trajectory) than if it caused 220 deaths (creating a downward trajectory). Behaviorally, we found that they allocated more money to cancer types with upward trajectories than to cancer types with downward trajectories. Although the trend effect on future estimates was very robust, the downstream consequences disappeared when the latest forecast varied greatly among the cancer types, suggesting that the effect of trajectories can be overridden by other information. From a theoretical perspective, this paper merges literatures of forecasting, risk perception and charitable giving. From an applied perspective, this paper suggests that charitable organizations could convey acuteness and severity of a specific cause by illustrating it with an upward trend, and that this has the potential to make people donate to that cause rather than other causes. 


\section{Endnotes}

${ }^{1}$ http://www.unhcr.org/figures-at-a-glance.html

${ }^{2}$ https://www.cancer.org/content/dam/cancer-org/research/cancer-facts-and-statistics/annualcancer-facts-and-figures/2017/cancer-facts-and-figures-2017.pdf

${ }^{3}$ http://www.natureworldnews.com/articles/29980/20161012/new-york-city-experience-9-footfloods-17-times-more.htm

${ }^{4} 16$ different versions of the questionnaire were distributed and each version appeared equally many times (see Appendix 1).

5 The descriptions of the different cancer types were inspired by descriptions found in the Swedish Cancer foundation annual report. Although the actual number of dead per year was fictive in order to maintain experimental control, the information about the cancer types and the number of dead in 2013 was kept close to the truth in order to avoid participants with experience of these cancer types to question the information.

${ }^{6}$ We asked about general severity and did thus not specify for participants whether severity referred to societal severity or severity for any individual suffering from the disease.

${ }^{7}$ See Appendix 3 for a summary of the results including these additional variables

${ }^{8}$ See Appendix 3 for results relating the post-choice justifications and the additional variables.

${ }^{9}$ With the current design, a random distribution would be $37.5 \%$ each for the downward and upward trajectory versions and $25 \%$ for the flat trajectory version.

${ }^{10}$ We changed the years from $2011 \rightarrow 2013 \rightarrow 2015$ (in Studies 1 and 2 ) to $2012 \rightarrow 2014 \rightarrow 2016$ (in Studies 3 and 4) because the data collections took place at different times.

${ }^{11}$ As this design did not rely on counterbalancing it was not necessary to replace the excluded participants in Study 4. 


\section{References}

Bachke, M. E., Alfnes, F., \& Wik, M. (2017). Information and donations to development aid projects. Journal of Behavioral and Experimental Economics. doi: /10.1016/j.socec.2016.04.015

Bartels, D. M. (2006). Proportion dominance: The generality and variability of favoring relative savings over absolute savings. Organizational Behavior and Human Decision Processes, 100(1), 76-95. doi:10.1016/j.obhdp.2005.10.004

Bekkers, R. (2003). Trust, accreditation, and philanthropy in the Netherlands. Nonprofit and Voluntary Sector Quarterly, 32(4), 596-615. doi:10.1177/0899764003258102

Bostrom, A., Anselin, L., \& Farris, J. (2008). Visualizing seismic risk and uncertainty. Annals of the New York Academy of Sciences, 1128(1), 29-40.

Chou, E. Y., \& Murnighan, J. K. (2013). Life or death decisions: Framing the call for help. PloS one, 8(3). doi:10.1371/journal.pone.0057351

Cotte, J., Coulter, R. A., \& Moore, M. (2005). Enhancing or disrupting guilt: the role of ad credibility and perceived manipulative intent. Journal of Business Research, 58(3), 361368.

Cryder, C. E., \& Loewenstein, G. (2012). Responsibility: The tie that binds. Journal of Experimental Social Psychology, 48(1), 441-445. doi:10.1016/j.jesp.2011.09.009

Cryder, C. E., Loewenstein, G., \& Scheines, R. (2013). The donor is in the details. Organizational Behavior and Human Decision Processes, 120(1), 15-23. doi:10.1016/j.obhdp.2012.08.002

Cryder, C. E., Loewenstein, G., \& Seltman, H. (2013). Goal gradient in helping behavior. Journal of Experimental Social Psychology, 49(6), 1078-1083. doi:http://dx.doi.org/10.1016/j.jesp.2013.07.003

Das, E., Kerkhof, P., \& Kuiper, J. (2008). Improving the effectiveness of fundraising messages: The impact of charity goal attainment, message framing, and evidence on persuasion. Journal of Applied Communication Research, 36(2), 161-175. doi:10.1080/00909880801922854

Davidai, S., \& Gilovich, T. (2016). The tide that lifts all focal boats: Asymmetric predictions of ascent and descent in rankings. Judgment and Decision Making, 11(1), 7.

Dickert, S., Kleber, J., Peters, E., \& Slovic, P. (2011). Numeracy as a precursor to pro-social behavior: The impact of numeracy and presentation format on the cognitive mechanisms underlying donation decisions. Judgment and Decision Making, 6(7), 638-650.

Erlandsson, A., Björklund, F., \& Bäckström, M. (2017). Choice-justifications after allocating resources in helping dilemmas. Judgment and Decision Making, 12(1), 60-80.

Erlandsson, A., Nilsson, A., \& Västfjäll, D. (2018). Attitudes and donation behavior when reading positive and negative charity appeals. Journal of Nonprofit \& Public Sector Marketing, 1-31. doi:10.1080/10495142.2018.1452828

Erlandsson, A., Västfjäll, D., Sundfelt, O., \& Slovic, P. (2016). Argument-inconsistency in charity appeals: Statistical information about the scope of the problem decrease helping toward a single identified victim but not helping toward many non-identified victims in a refugee crisis context. Journal of Economic Psychology, 56, 126-140. doi:http://dx.doi.org/10.1016/j.joep.2016.06.007

Evangelidis, I., \& van den Bergh, B. (2013). The number of fatalities drives disaster aid increasing sensitivity to people in need. Psychological Science. doi:10.1177/0956797613490748 
Fetherstonhaugh, D., Slovic, P., Johnson, S., \& Friedrich, J. (1997). Insensitivity to the value of human life: A study of psychophysical numbing. Journal of Risk and Uncertainty, 14(3), 283-300. doi:10.1023/a:1007744326393

Freedman, D., Pisani, R., \& Purves, R. (2007). Statistics (4th ed.). New York: W.W Norton and Company.

Harvey, N., \& Bolger, F. (1996). Graphs versus tables: Effects of data presentation format on judgemental forecasting. International Journal of Forecasting, 12(1), 119-137.

Harvey, N., \& Reimers, S. (2013). Trend damping: Under-adjustment, experimental artifact, or adaptation to features of the natural environment? Journal of Experimental Psychology: Learning, Memory, and Cognition, 39(2), 589.

Hohle, S. M., \& Teigen, K. H. (2015). Forecasting forecasts: The trend effect. Judgment and Decision Making, 10(5), 416-428.

Hohle, S. M., \& Teigen, K. H. (2018). When probabilities change: perceptions and implications of trends in uncertain climate forecasts. Journal of Risk Research, 1-15.

Hsee, C. K., \& Zhang, J. (2010). General evaluability theory. Perspectives on Psychological Science, 5(4), 343-355. doi:10.1177/1745691610374586

Hubbard, T. L. (2014). Forms of momentum across space: Representational, operational, and attentional. Psychonomic Bulletin \& Review, 21(6), 1371-1403.

Kahneman, D. (2003). A perspective on judgment and choice: Mapping bounded rationality. American psychologist, 58(9), 697-720.

Kleber, J., Dickert, S., Peters, E., \& Florack, A. (2013). Same numbers, different meanings: How numeracy influences the importance of numbers for pro-social behavior. Journal of Experimental Social Psychology, 49(4), 699-705. doi:10.1016/j.jesp.2013.02.009

Kogut, T., \& Ritov, I. (2011). The identifiable victim effect: Causes and boundary conditions. In D. M. Oppenheimer \& C. Y. Olivola (Eds.), The Science of Giving: Experimental Approaches to the Study of Charity. New York: Taylor \& Francis Group.

Lesner, T. H., \& Rasmussen, O. D. (2014). The identifiable victim effect in charitable giving: evidence from a natural field experiment. Applied Economics, 46(36), 4409-4430. doi:10.1080/00036846.2014.962226

Lewandowsky, S. (2011). Popular consensus: Climate change is set to continue. Psychological Science, 22(4), 460-463.

Loewenstein, G. F., \& Prelec, D. (1993). Preferences for sequences of outcomes. Psychological review, $100(1), 91$.

Maglio, S. J., \& Polman, E. (2016). Revising probability estimates: Why increasing likelihood means increasing impact. Journal of Personality and Social Psychology, 111(2), 141-158. doi: $10.1037 / \mathrm{pspa0000058}$

Markman, K. D., \& Guenther, C. L. (2007). Psychological momentum: Intuitive physics and naive beliefs. Personality and Social Psychology Bulletin, 33(6), 800-812.

Mata, A. (2016). Proportion dominance in valuing lives: The role of deliberative thinking. Judgment and Decision Making, 11(5), 441-448.

Mortensen, C. R., Neel, R., Cialdini, R. B., Jaeger, C. M., Jacobson, R. P., \& Ringel, M. M. (2017). Trending norms: A lever for encouraging behaviors performed by the minority. Social Psychological and Personality Science, 1948550617734615.

McShane, B. B., \& Böckenholt, U. (2017). Single-paper meta-analysis: Benefits for study summary, theory testing, and replicability. Journal of Consumer Research, 43(6), 10481063. 
Peters, E., Dieckmann, N. F., Västfjäll, D., Mertz, C. K., Slovic, P., \& Hibbard, J. H. (2009). Bringing meaning to numbers: The impact of evaluative categories on decisions. Journal of Experimental Psychology: Applied, 15(3), 213-227. doi:10.1037/a0016978

Peters, E., Västfjäll, D., Slovic, P., Mertz, C. K., Mazzocco, K., \& Dickert, S. (2006). Numeracy and Decision Making. Psychological Science, 17(5), 407-413. doi:10.1111/j.14679280.2006.01720.x

Pettit, N. C., Sivanathan, N., Gladstone, E., \& Marr, J. C. (2013). Rising stars and sinking ships consequences of status momentum. Psychological Science, 24(8), 1579-1584.

Reyna, V. F. (2004). How people make decisions that involve risk: A dual-processes approach. Current Directions in Psychological Science, 13(2), 60-66.

Reyna, V. F., \& Brainerd, C. J. (1995). Fuzzy-trace theory: An interim synthesis. Learning and Individual Differences, 7(1), 1-75. doi:10.1016/1041-6080(95)90031-4

Shen, L., \& Hsee, C. K. (2017). Numerical nudging: Using an accelerating score to enhance performance. Psychological Science, 28(8), 1077-1086. doi:10.1177/0956797617700497

Slovic, P. (1975). Choice between equally valued alternatives. Journal of Experimental Psychology: Human Perception and Performance, 1(3), 280-287. doi:10.1037/00961523.1.3.280

Slovic, P. (2007). "If I look at the mass I will never act": Psychic numbing and genocide. Judgment and Decision Making, 2(2), 79-95.

Small, D. A., Loewenstein, G., \& Slovic, P. (2007). Sympathy and callousness: The impact of deliberative thought on donations to identifiable and statistical victims. Organizational Behavior and Human Decision Processes, 102(2), 143-153. doi:10.1016/j.obhdp.2006.01.005

Tversky, A., Sattath, S., \& Slovic, P. (1988). Contingent weighting in judgment and choice. Psychological review, 95(3), 371-384. doi:10.1037/0033-295x.95.3.371

Västfjäll, D., Slovic, P., \& Mayorga, M. (2015). Pseudoinefficacy: Negative feelings from children who cannot be helped reduce warm glow for children who can be helped. Frontiers in Psychology, 6. doi:10.3389/fpsyg.2015.00616

Västfjäll, D., Slovic, P., Mayorga, M., \& Peters, E. (2014). Compassion fade: Affect and charity are greatest for a single child in need. PloS one, 9(6). doi:10.1371/journal.pone.0100115 


\section{THE TREND EFFECT ON SEVERITY AND HELP-ALLOCATIONS}

Table 1

Estimated number of deaths and perceived severity for the different trajectory versions in Study 1.

\begin{tabular}{|c|c|c|c|c|c|c|}
\hline & \multicolumn{3}{|c|}{ Estimated number of deaths in 2015} & \multicolumn{3}{|c|}{ Perceived severity (scale 0-1) } \\
\hline & $\begin{array}{c}\text { Downward } \\
\text { trajectory }\end{array}$ & $\begin{array}{c}\text { Flat } \\
\text { trajectory }\end{array}$ & $\begin{array}{l}\text { Upward } \\
\text { trajectory }\end{array}$ & $\begin{array}{l}\text { Downward } \\
\text { trajectory }\end{array}$ & $\begin{array}{c}\text { Flat } \\
\text { trajectory }\end{array}$ & $\begin{array}{l}\text { Upward } \\
\text { trajectory }\end{array}$ \\
\hline $\begin{array}{l}\text { Hodgkin's } \\
\text { Lymphoma } \\
\text { [196 dead in } \\
2013, \pm 19]\end{array}$ & $\begin{array}{l}185.33^{a} \\
(20.30)\end{array}$ & $\begin{array}{l}187.46^{\mathrm{a}} \\
(20.51)\end{array}$ & $\begin{array}{l}199.90^{\mathrm{b}} \\
(21.15)\end{array}$ & $\begin{array}{c}0.619^{\mathrm{a}} \\
(0.196)\end{array}$ & $\begin{array}{l}0.639^{\mathrm{ab}} \\
(0.211)\end{array}$ & $\begin{array}{c}0.709^{\mathrm{b}} \\
(0.149)\end{array}$ \\
\hline $\begin{array}{l}\text { Pancreatic } \\
\text { cancer } \\
{[204 \text { dead in }} \\
2013, \pm 56]\end{array}$ & $\begin{array}{l}185.37^{\mathrm{a}} \\
(32.29)\end{array}$ & $\begin{array}{l}204.65^{\mathrm{b}} \\
(18.28)\end{array}$ & $\begin{array}{l}215.03^{\mathrm{b}} \\
(35.52)\end{array}$ & $\begin{array}{c}0.670^{\mathrm{a}} \\
(0.209)\end{array}$ & $\begin{array}{c}0.667^{\mathrm{a}} \\
(0.172)\end{array}$ & $\begin{array}{r}0.697^{\mathrm{a}} \\
(0.185)\end{array}$ \\
\hline $\begin{array}{l}\text { Gall bladder } \\
\text { cancer } \\
{[199 \text { dead in }} \\
2013, \pm 54]\end{array}$ & $\begin{array}{l}174.72^{\mathrm{a}} \\
(31.45)\end{array}$ & $\begin{array}{l}196.13^{b} \\
(16.31)\end{array}$ & $\begin{array}{l}205.63^{\mathrm{b}} \\
(32.27)\end{array}$ & $\begin{array}{c}0.576^{\mathrm{a}} \\
(0.205)\end{array}$ & $\begin{array}{l}0.594^{\mathrm{a}} \\
(0.209)\end{array}$ & $\begin{array}{c}0.676^{\mathrm{b}} \\
(0.186)\end{array}$ \\
\hline $\begin{array}{l}\text { Endocrine } \\
\text { gland tumors } \\
{[201 \text { dead in }} \\
2013, \pm 21]\end{array}$ & $\begin{array}{l}192.53^{\mathrm{a}} \\
(20.80)\end{array}$ & $\begin{array}{l}200.15^{\mathrm{a}} \\
(23.89)\end{array}$ & $\begin{array}{l}215.31^{\mathrm{b}} \\
(17.39)\end{array}$ & $\begin{array}{c}0.635^{\mathrm{a}} \\
(0.174)\end{array}$ & $\begin{array}{c}0.687^{\mathrm{a}} \\
(0.183)\end{array}$ & $\begin{array}{c}0.642^{\mathrm{a}} \\
(0.165)\end{array}$ \\
\hline
\end{tabular}

Note. Numbers within brackets illustrate the number of dead in 2013, and the change in number of dead between 2011 and 2013 in the downward/upward trajectory version). Different subscripts indicate that the mean of the trajectory versions differed significantly $(p<.05$, Bonferroni-corrected). 
Table 2

Estimated number of deaths, perceived severity and number of allocations for the different trajectory versions in Study 2.

\begin{tabular}{|c|c|c|c|c|c|c|c|c|c|c|}
\hline \multirow[b]{3}{*}{$\begin{array}{l}\text { Hodgkin's } \\
\text { Lymphoma } \\
\text { [196 deaths } \\
\text { in } 2013, \pm 19 \text { ] }\end{array}$} & \multicolumn{3}{|c|}{$\begin{array}{l}\text { Estimated number } \\
\text { of deaths in } 2015\end{array}$} & \multicolumn{3}{|c|}{$\begin{array}{c}\text { Perceived severity } \\
\text { (Scale 0-1) }\end{array}$} & \multicolumn{4}{|c|}{$\begin{array}{l}\text { Allocation } \\
\text { decision }\end{array}$} \\
\hline & $\begin{array}{c}\text { Downward } \\
\text { trajectory }\end{array}$ & $\begin{array}{c}\text { Flat } \\
\text { trajectory }\end{array}$ & $\begin{array}{l}\text { Upward } \\
\text { trajectory }\end{array}$ & $\begin{array}{c}\text { Downward } \\
\text { trajectory }\end{array}$ & $\begin{array}{c}\text { Flat } \\
\text { trajectory }\end{array}$ & $\begin{array}{l}\text { Upward } \\
\text { trajectory }\end{array}$ & $\begin{array}{l}\text { Downward } \\
\text { trajectory }\end{array}$ & $\begin{array}{c}\text { Flat } \\
\text { trajectory }\end{array}$ & $\begin{array}{l}\text { Upward } \\
\text { trajectory }\end{array}$ & $\chi^{2}(2)$ \\
\hline & $\begin{array}{l}181.28^{\mathrm{a}} \\
(20.06)\end{array}$ & $\begin{array}{l}196.26^{b} \\
(19.07)\end{array}$ & $\begin{array}{l}204.28^{c} \\
(19.07)\end{array}$ & $\begin{array}{l}0.590^{\mathrm{a}} \\
(0.205)\end{array}$ & $\begin{array}{l}0.572^{\mathrm{a}} \\
(0.228)\end{array}$ & $\begin{array}{l}0.611^{\mathrm{a}} \\
(0.187)\end{array}$ & $\begin{array}{c}18 \\
(34.6 \%)\end{array}$ & $\begin{array}{c}12 \\
(23.1 \%)\end{array}$ & $\begin{array}{c}22 \\
(42.3 \%)\end{array}$ & $\begin{array}{c}0.66 \\
p=.721\end{array}$ \\
\hline $\begin{array}{l}\text { Pancreatic } \\
\text { cancer } \\
\text { [204 deaths } \\
\text { in } 2013, \pm 56]\end{array}$ & $\begin{array}{l}194.43^{\mathrm{a}} \\
(29.00)\end{array}$ & $\begin{array}{l}206.63^{b} \\
(11.12)\end{array}$ & $\begin{array}{l}234.87^{c} \\
(39.02)\end{array}$ & $\begin{array}{l}0.622^{\mathrm{a}} \\
(0.220)\end{array}$ & $\begin{array}{l}0.656^{\mathrm{ab}} \\
(0.194)\end{array}$ & $\begin{array}{l}0.704^{b} \\
(0.176)\end{array}$ & $\begin{array}{c}41 \\
(29.7 \%)\end{array}$ & $\begin{array}{c}28 \\
(20.3 \%)\end{array}$ & $\begin{array}{c}69 \\
(50.0 \%)\end{array}$ & $\begin{array}{c}17.03 \\
p<.001\end{array}$ \\
\hline $\begin{array}{l}\text { Gall bladder } \\
\text { cancer } \\
{[199 \text { deaths }} \\
\text { in } 2013, \pm 54]\end{array}$ & $\begin{array}{l}181.68^{\mathrm{a}} \\
(37.73)\end{array}$ & $\begin{array}{l}195.65^{b} \\
(15.00)\end{array}$ & $\begin{array}{l}216.04^{\mathrm{c}} \\
(35.29)\end{array}$ & $\begin{array}{l}0.528^{\mathrm{a}} \\
(0.183)\end{array}$ & $\begin{array}{l}0.544^{\mathrm{a}} \\
(0.194)\end{array}$ & $\begin{array}{l}0.588^{a} \\
(0.192)\end{array}$ & $\begin{array}{c}6 \\
(14.3 \%)\end{array}$ & $\begin{array}{c}1 \\
(2.4 \%)\end{array}$ & $\begin{array}{c}35 \\
(83.3 \%)\end{array}$ & $\begin{array}{c}45.79 \\
p<.001\end{array}$ \\
\hline $\begin{array}{l}\text { Endocrine } \\
\text { gland tumors } \\
\text { [201 deaths } \\
\text { in } 2013, \pm 21]\end{array}$ & $\begin{array}{l}195.71^{\mathrm{a}} \\
(22.80)\end{array}$ & $\begin{array}{l}208.04^{b} \\
(24.34)\end{array}$ & $\begin{array}{l}217.40^{c} \\
(26.24)\end{array}$ & $\begin{array}{l}0.552^{\mathrm{a}} \\
(0.187)\end{array}$ & $\begin{array}{l}0.582^{\mathrm{a}} \\
(0.205)\end{array}$ & $\begin{array}{l}0.596^{\mathrm{a}} \\
(0.182)\end{array}$ & $\begin{array}{c}8 \\
(15.7 \%)\end{array}$ & $\begin{array}{c}13 \\
(25.5 \%)\end{array}$ & $\begin{array}{c}30 \\
(58.8 \%)\end{array}$ & $\begin{array}{c}15.46 \\
p<.001\end{array}$ \\
\hline
\end{tabular}

Note. Numbers within brackets illustrate the number of deaths in 2013, and the change in number of deaths between 2011 and 2013 in the downward/upward trajectory version). Different subscripts indicate that the mean of the trajectory versions differed significantly ( $p<.05$, Bonferroni-corrected). A random distribution in the allocation decision would be $37.5 \%$ for the downward and upward trajectory versions and $25 \%$ for the flat trajectory version. 
Table 3

Estimated death risk, perceived severity and number of allocations for the different trajectory versions in Study 3.

\begin{tabular}{|c|c|c|c|c|c|c|c|c|c|c|}
\hline \multirow[b]{3}{*}{$\begin{array}{l}\text { Hodgkin's } \\
\text { Lymphoma } \\
{[25 \% \text { death }} \\
\text { risk, } \pm 16 \% \text { ] }\end{array}$} & \multicolumn{3}{|c|}{$\begin{array}{c}\text { Estimated death risk } \\
\text { in } 2016\end{array}$} & \multicolumn{3}{|c|}{$\begin{array}{c}\text { Perceived severity } \\
(\text { Scale } 0-1)\end{array}$} & \multicolumn{4}{|c|}{$\begin{array}{l}\text { Allocation } \\
\text { decision }\end{array}$} \\
\hline & $\begin{array}{c}\text { Downward } \\
\text { trajectory }\end{array}$ & $\begin{array}{c}\text { Flat } \\
\text { trajectory }\end{array}$ & $\begin{array}{l}\text { Upward } \\
\text { trajectory }\end{array}$ & $\begin{array}{c}\text { Downward } \\
\text { trajectory }\end{array}$ & $\begin{array}{c}\text { Flat } \\
\text { trajectory }\end{array}$ & $\begin{array}{l}\text { Upward } \\
\text { trajectory }\end{array}$ & $\begin{array}{c}\text { Downward } \\
\text { trajectory }\end{array}$ & $\begin{array}{c}\text { Flat } \\
\text { trajectory }\end{array}$ & $\begin{array}{l}\text { Upward } \\
\text { trajectory }\end{array}$ & $\chi^{2}(2)$ \\
\hline & $\begin{array}{c}19.88 \%{ }^{\mathrm{a}} \\
(5.57)\end{array}$ & $\begin{array}{c}24.86 \%^{\mathrm{b}} \\
(3.61)\end{array}$ & $\begin{array}{c}28.76 \%^{\mathrm{c}} \\
(8.72)\end{array}$ & $\begin{array}{l}0.539^{\mathrm{a}} \\
(0.204)\end{array}$ & $\begin{array}{l}0.583^{\mathrm{ab}} \\
(0.191)\end{array}$ & $\begin{array}{l}0.632^{\mathrm{b}} \\
(0.191)\end{array}$ & $\begin{array}{c}24 \\
(22.9 \%)\end{array}$ & $\begin{array}{c}24 \\
(22.9 \%)\end{array}$ & $\begin{array}{c}57 \\
(54.3 \%)\end{array}$ & $\begin{array}{c}14.09 \\
p=.001\end{array}$ \\
\hline $\begin{array}{l}\text { Mouth } \\
\text { cancer } \\
{[23 \% \text { death }} \\
\text { risk, } \pm 13 \% \text { ] }\end{array}$ & $\begin{array}{c}19.35 \%{ }^{\mathrm{a}} \\
(4.91)\end{array}$ & $\begin{array}{c}22.54 \%^{b} \\
(2.28)\end{array}$ & $\begin{array}{c}26.39 \% \\
(8.08)\end{array}$ & $\begin{array}{l}0.559^{\mathrm{a}} \\
(0.210)\end{array}$ & $\begin{array}{l}0.510^{\mathrm{a}} \\
(0.196)\end{array}$ & $\begin{array}{l}0.530^{\mathrm{a}} \\
(0.213)\end{array}$ & $\begin{array}{c}14 \\
(23.7 \%)\end{array}$ & $\begin{array}{c}9 \\
(15.3 \%)\end{array}$ & $\begin{array}{c}36 \\
(61.0 \%)\end{array}$ & $\begin{array}{c}13.93 \\
p=.001\end{array}$ \\
\hline $\begin{array}{l}\text { Sarkoma } \\
{[24 \% \text { death }} \\
\text { risk, } \pm 10 \%]\end{array}$ & $\begin{array}{c}21.11 \%^{\mathrm{a}} \\
(6.51)\end{array}$ & $\begin{array}{c}23.36 \%^{\mathrm{b}} \\
(2.80)\end{array}$ & $\begin{array}{c}26.88 \%{ }^{\mathrm{c}} \\
(5.93)\end{array}$ & $\begin{array}{l}0.567^{\mathrm{a}} \\
(0.194)\end{array}$ & $\begin{array}{l}0.610^{\mathrm{a}} \\
(0.216)\end{array}$ & $\begin{array}{l}0.610^{\mathrm{a}} \\
(0.193)\end{array}$ & $\begin{array}{c}18 \\
(23.4 \%)\end{array}$ & $\begin{array}{c}14 \\
(18.2 \%)\end{array}$ & $\begin{array}{c}45 \\
(58.4 \%)\end{array}$ & $\begin{array}{c}14.53 \\
p=.001\end{array}$ \\
\hline $\begin{array}{l}\text { Endocrine } \\
\text { gland tumors } \\
{[22 \% \text { death }} \\
\text { risk, } \pm 15 \%]\end{array}$ & $\begin{array}{c}17.71 \%{ }^{\mathrm{a}} \\
(5.32)\end{array}$ & $\begin{array}{c}21.70 \%^{b} \\
(3.12)\end{array}$ & $\begin{array}{c}26.90 \%{ }^{c} \\
(9.70)\end{array}$ & $\begin{array}{l}0.552^{\mathrm{a}} \\
(0.194)\end{array}$ & $\begin{array}{l}0.581^{\mathrm{a}} \\
(0.185)\end{array}$ & $\begin{array}{l}0.604^{\mathrm{a}} \\
(0.196)\end{array}$ & $\begin{array}{c}21 \\
(31.3 \%)\end{array}$ & $\begin{array}{c}14 \\
(20.9 \%)\end{array}$ & $\begin{array}{c}32 \\
(47.8 \%)\end{array}$ & $\begin{array}{c}3.01 \\
p=.222\end{array}$ \\
\hline
\end{tabular}


THE EFFECT OF TRENDS ON PERCEIVED SEVERITY AND HELP-ALLOCATIONS

Table 4

Estimated death risk in 2016 and perceived severity of Hodgkin's Lymphoma, and the number of allocations given to Hodgkin's Lymphoma for the different trajectory versions in Study 4.

\begin{tabular}{|c|c|c|c|c|c|c|}
\hline & \multicolumn{2}{|c|}{$\begin{array}{c}\text { Estimated death risk of Hodgkin's } \\
\text { Lymphoma } \\
\text { in } 2016 \\
\end{array}$} & \multicolumn{2}{|c|}{$\begin{array}{c}\text { Perceived severity of Hodgkin's } \\
\text { Lymphoma } \\
(0-1)\end{array}$} & \multicolumn{2}{|c|}{$\begin{array}{l}\text { Participants allocating to Hodgkin's } \\
\text { Lymphoma }\end{array}$} \\
\hline & $\begin{array}{c}\text { Downward } \\
\text { trajectory in } \\
\text { Hodgkin's } \\
(30 \% \rightarrow 18 \%)\end{array}$ & $\begin{array}{l}\text { Upward } \\
\text { trajectory in } \\
\text { Hodgkin's } \\
(6 \% \rightarrow 18 \%)\end{array}$ & $\begin{array}{c}\text { Downward } \\
\text { trajectory in } \\
\text { Hodgkin's } \\
(30 \% \rightarrow 18 \%)\end{array}$ & $\begin{array}{l}\text { Upward } \\
\text { trajectory in } \\
\text { Hodgkin's } \\
(6 \% \rightarrow 18 \%)\end{array}$ & $\begin{array}{c}\text { Downward } \\
\text { trajectory in } \\
\text { Hodgkin's } \\
(30 \% \rightarrow 18 \%)\end{array}$ & $\begin{array}{l}\text { Upward } \\
\text { trajectory in } \\
\text { Hodgkin's } \\
(6 \% \rightarrow 18 \%)\end{array}$ \\
\hline $\begin{array}{l}\text { Lower death risk of } \\
\text { Endocrine gland } \\
\text { tumors }[17 \% \rightarrow 17 \%]\end{array}$ & $\begin{array}{l}14.94 \\
(5.31)\end{array}$ & $\begin{array}{l}21.36 \\
(6.96)\end{array}$ & $\begin{array}{l}0.524 \\
(0.174)\end{array}$ & $\begin{array}{c}0.569 \\
(0.158)\end{array}$ & $\begin{array}{c}52 \\
(36.9 \%)\end{array}$ & $\begin{array}{c}105 \\
(74.5 \%)\end{array}$ \\
\hline $\begin{array}{l}\text { Higher death risk of } \\
\text { Endocrine gland } \\
\text { tumors }[19 \% \rightarrow 19 \%]\end{array}$ & $\begin{array}{l}13.72 \\
(4.33)\end{array}$ & $\begin{array}{l}21.43 \\
(6.12)\end{array}$ & $\begin{array}{c}0.531 \\
(0.182)\end{array}$ & $\begin{array}{c}0.557 \\
(0.192)\end{array}$ & $\begin{array}{c}40 \\
(28.6 \%)\end{array}$ & $\begin{array}{c}105 \\
(72.9 \%)\end{array}$ \\
\hline
\end{tabular}

Note. Numbers within brackets illustrate the expert-estimated death risks in 2012 and 2014 for Hodgkin's lymphoma (columns) or the expert-estimated death risks in 2012 and 2014 for Endocrine gland tumors (rows). Ratings of estimated death risk and perceived severity for endocrine gland tumors are reported in Appendix 3. 
THE EFFECT OF TRENDS ON PERCEIVED SEVERITY AND HELP-ALLOCATIONS

Table X

Estimated chance of survival and perceived severity for the different trajectory versions in additional Study X.

\begin{tabular}{|c|c|c|c|c|c|c|}
\hline & \multicolumn{3}{|c|}{ Estimated chance of survival in 2015} & \multicolumn{3}{|c|}{ Perceived severity (scale 0-1) } \\
\hline & $\begin{array}{c}\text { Downward } \\
\text { trajectory }\end{array}$ & $\begin{array}{c}\text { Flat } \\
\text { trajectory }\end{array}$ & $\begin{array}{c}\text { Upward } \\
\text { trajectory }\end{array}$ & $\begin{array}{l}\text { Downward } \\
\text { trajectory }\end{array}$ & $\begin{array}{c}\text { Flat } \\
\text { trajectory }\end{array}$ & $\begin{array}{l}\text { Upward } \\
\text { trajectory }\end{array}$ \\
\hline $\begin{array}{l}\text { Hodgkin's Lymphoma } \\
\text { [51\% chance of survival in } 2013 \text {, } \\
\pm 10 \% \text { ] }\end{array}$ & $\begin{array}{c}48.05 \%{ }^{\mathrm{a}} \\
(9.18)\end{array}$ & $\begin{array}{c}53.15 \%^{\mathrm{b}} \\
(5.27)\end{array}$ & $\begin{array}{l}58.14 \%^{\mathrm{c}} \\
(5.23)\end{array}$ & $\begin{array}{c}0.650^{\mathrm{a}} \\
(0.150)\end{array}$ & $\begin{array}{c}0.654^{\mathrm{a}} \\
(0.136)\end{array}$ & $\begin{array}{c}0.620^{\mathrm{a}} \\
(0.180)\end{array}$ \\
\hline $\begin{array}{l}\text { Pancreatic cancer } \\
{[6 \% \text { chance of survival in } 2013 \text {, }} \\
\pm 5 \%]\end{array}$ & $\begin{array}{l}7.07 \%{ }^{\mathrm{a}} \\
(4.02)\end{array}$ & $\begin{array}{c}7.30 \%{ }^{\mathrm{a}} \\
(1.77)\end{array}$ & $\begin{array}{c}10.74 \% \mathrm{~b} \\
(3.84)\end{array}$ & $\begin{array}{c}0.864^{\mathrm{a}} \\
(0.124)\end{array}$ & $\begin{array}{c}0.890^{\mathrm{a}} \\
(0.076)\end{array}$ & $\begin{array}{c}0.895^{\mathrm{a}} \\
(0.086)\end{array}$ \\
\hline $\begin{array}{l}\text { Gall bladder cancer } \\
\text { [ } 49 \% \text { chance of survival in } 2013 \text {, } \\
\pm 11 \% \text { ] }\end{array}$ & $\begin{array}{c}46.78 \% \mathrm{a}^{\mathrm{a}} \\
(7.91)\end{array}$ & $\begin{array}{c}51.08 \% \mathrm{~b} \\
(3.25)\end{array}$ & $\begin{array}{c}54.93 \% \mathrm{c} \\
(5.87)\end{array}$ & $\begin{array}{c}0.696^{\mathrm{a}} \\
(0.121)\end{array}$ & $\begin{array}{c}0.627^{\mathrm{a}} \\
(0.176)\end{array}$ & $\begin{array}{c}0.654^{\mathrm{a}} \\
(0.174)\end{array}$ \\
\hline $\begin{array}{l}\text { Endocrine gland tumors } \\
\text { [94\% chance of survival in } 2013 \text {, } \\
\pm 5 \% \text { ] }\end{array}$ & $\begin{array}{c}91.64 \%{ }^{\mathrm{a}} \\
(3.98)\end{array}$ & $\begin{array}{c}94.52 \% \mathrm{~b} \\
(2.73)\end{array}$ & $\begin{array}{c}94.65 \% \mathrm{~b} \\
(3.76)\end{array}$ & $\begin{array}{l}0.364^{\mathrm{a}} \\
(0.234)\end{array}$ & $\begin{array}{c}0.365^{\mathrm{a}} \\
(0.242)\end{array}$ & $\begin{array}{c}0.320^{\mathrm{a}} \\
(0.198)\end{array}$ \\
\hline
\end{tabular}


Table Y

Estimated death risk, perceived severity and number of allocated lottery tickets for the different trajectory versions in additional Study Y.

\begin{tabular}{|c|c|c|c|c|c|c|c|c|c|c|}
\hline & \multicolumn{3}{|c|}{$\begin{array}{l}\text { Estimated death risk } \\
\text { in } 2015\end{array}$} & \multicolumn{3}{|c|}{$\begin{array}{l}\text { Perceived severity } \\
\quad(\text { Scale } 0-1)\end{array}$} & \multicolumn{4}{|c|}{$\begin{array}{c}\text { Donation decision } \\
\text { (number of lottery tickets) }\end{array}$} \\
\hline & $\begin{array}{l}\text { Downward } \\
\text { trajectory }\end{array}$ & $\begin{array}{l}\text { Flat } \\
\text { trajectory }\end{array}$ & $\begin{array}{l}\text { Upward } \\
\text { trajectory }\end{array}$ & $\begin{array}{l}\text { Downward } \\
\text { trajectory }\end{array}$ & $\begin{array}{l}\text { Flat } \\
\text { trajectory }\end{array}$ & $\begin{array}{l}\text { Upward } \\
\text { trajectory }\end{array}$ & $\begin{array}{l}\text { Downward } \\
\text { trajectory }\end{array}$ & $\begin{array}{c}\text { Flat } \\
\text { trajectory }\end{array}$ & $\begin{array}{l}\text { Upward } \\
\text { trajectory }\end{array}$ & $\chi^{2}(2)$ \\
\hline $\begin{array}{l}\text { Hodgkin's } \\
\text { Lymphoma } \\
{[49 \% \text { death }} \\
\text { risk, } \pm 10 \% \text { ] }\end{array}$ & $\begin{array}{c}43.56 \%{ }^{\mathrm{a}} \\
(4.40)\end{array}$ & $\begin{array}{c}48.39 \%{ }^{\mathrm{b}} \\
(2.02)\end{array}$ & $\begin{array}{l}51.87 \%{ }^{c} \\
(6.68)\end{array}$ & $\begin{array}{l}0.697^{\mathrm{a}} \\
(0.128)\end{array}$ & $\begin{array}{l}0.658^{a} \\
(0.151)\end{array}$ & $\begin{array}{l}0.655^{\mathrm{a}} \\
(0.156)\end{array}$ & $\begin{array}{c}10 \\
(45.5 \%)\end{array}$ & $\begin{array}{c}6 \\
(27.3 \%)\end{array}$ & $\begin{array}{c}8 \\
(36.4 \%)\end{array}$ & $\begin{array}{c}0.22 \\
p=.896\end{array}$ \\
\hline $\begin{array}{l}\text { Pancreatic } \\
\text { cancer } \\
{[94 \% \text { death }} \\
\text { risk, } \pm 6 \%]\end{array}$ & $\begin{array}{l}89.06 \%{ }^{a} \\
(4.48)\end{array}$ & $\begin{array}{l}93.09 \% \mathrm{~b} \\
(1.77)\end{array}$ & $\begin{array}{l}92.81 \% \mathrm{~b} \\
(3.12)\end{array}$ & $\begin{array}{l}0.861^{\mathrm{a}} \\
(0.134)\end{array}$ & $\begin{array}{l}0.889^{\mathrm{a}} \\
(0.098)\end{array}$ & $\begin{array}{l}0.890^{\mathrm{a}} \\
(0.087)\end{array}$ & $\begin{array}{c}29 \\
(30.2 \%)\end{array}$ & $\begin{array}{c}29 \\
(30.2 \%)\end{array}$ & $\begin{array}{c}38 \\
(39.9 \%)\end{array}$ & $\begin{array}{c}2.51 \\
p=.285\end{array}$ \\
\hline $\begin{array}{l}\text { Gall bladder } \\
\text { cancer } \\
{[51 \% \text { death }} \\
\text { risk, } \pm 11 \%]\end{array}$ & $\begin{array}{c}44.99 \%{ }^{\mathrm{a}} \\
(4.41)\end{array}$ & $\begin{array}{c}49.98 \% \mathrm{~b} \\
(2.73)\end{array}$ & $\begin{array}{c}51.96 \% \text { b } \\
(5.72)\end{array}$ & $\begin{array}{l}0.661^{a} \\
(0.157)\end{array}$ & $\begin{array}{l}0.674^{\mathrm{a}} \\
(0.162)\end{array}$ & $\begin{array}{l}0.678^{a} \\
(0.155)\end{array}$ & $\begin{array}{c}10 \\
(31.3 \%)\end{array}$ & $\begin{array}{c}8 \\
(25 \%)\end{array}$ & $\begin{array}{c}16 \\
(50 \%)\end{array}$ & $\begin{array}{c}1.45 \\
p=.484\end{array}$ \\
\hline $\begin{array}{l}\text { Endocrine } \\
\text { gland tumors } \\
\text { [7\% death } \\
\text { risk, } \pm 7 \%]\end{array}$ & $\begin{array}{c}5.77 \%{ }^{\mathrm{a}} \\
(1.82)\end{array}$ & $\begin{array}{c}6.72 \%{ }^{\mathrm{a}} \\
(1.06)\end{array}$ & $\begin{array}{c}8.89 \% \text { b } \\
(3.17)\end{array}$ & $\begin{array}{l}0.318^{a} \\
(0.154)\end{array}$ & $\begin{array}{l}0.367^{\mathrm{a}} \\
(0.215)\end{array}$ & $\begin{array}{l}0.304^{\mathrm{a}} \\
(0.177)\end{array}$ & $\begin{array}{c}3 \\
(42.9 \%)\end{array}$ & $\begin{array}{c}2 \\
(28.6 \%)\end{array}$ & $\begin{array}{c}2 \\
(28.6)\end{array}$ & $\begin{array}{c}0.24 \\
p=.887\end{array}$ \\
\hline
\end{tabular}

Note. Numbers within brackets illustrate the estimated death risk in 2013, and the change in death risk between 2011 and 2013 in the downward/upward trajectory versions. Different subscripts indicate that the mean of the trajectory versions differed significantly $(p<.05$, Bonferroni-corrected). A random distribution in the allocation decision would be $37.5 \%$ for the downward and upward trajectory versions and $25 \%$ for the flat trajectory version. 
THE EFFECT OF TRENDS ON PERCEIVED SEVERITY AND HELP-ALLOCATIONS

Table Z

Estimated death risk, perceived severity and amount earmarked to Hodgkin's Lymphoma for the different trajectory versions in additional Study Z.

\begin{tabular}{|c|c|c|c|c|c|c|}
\hline & \multicolumn{2}{|c|}{$\begin{array}{l}\text { Estimated death risk of } \\
\text { Hodgkin's Lymphoma } \\
\text { in } 2016\end{array}$} & \multicolumn{2}{|c|}{$\begin{array}{c}\text { Perceived severity of } \\
\text { Hodgkin's Lymphoma } \\
(0-1)\end{array}$} & \multicolumn{2}{|c|}{$\begin{array}{c}\text { Mean amount } \\
\text { earmarked to } \\
\text { Hodgkin's Lymphoma }\end{array}$} \\
\hline & $\begin{array}{c}\text { Downward } \\
\text { trajectory }\end{array}$ & $\begin{array}{l}\text { Upward } \\
\text { trajectory }\end{array}$ & $\begin{array}{c}\text { Downward } \\
\text { trajectory }\end{array}$ & $\begin{array}{l}\text { Upward } \\
\text { trajectory }\end{array}$ & $\begin{array}{c}\text { Downward } \\
\text { trajectory }\end{array}$ & $\begin{array}{c}\text { Upward } \\
\text { trajectory }\end{array}$ \\
\hline $\begin{array}{l}\text { Low death risk } \\
\text { [18\% in 2014] }\end{array}$ & $\begin{array}{l}16.78 \\
(8.16)\end{array}$ & $\begin{array}{l}24.01 \\
(9.78)\end{array}$ & $\begin{array}{c}0.562 \\
(0.180)\end{array}$ & $\begin{array}{c}0.620 \\
(0.185)\end{array}$ & $\begin{array}{l}\text { 3.47 SEK } \\
(1.58)\end{array}$ & $\begin{array}{c}\text { 3.68 SEK } \\
(1.55)\end{array}$ \\
\hline $\begin{array}{l}\text { High death risk } \\
\text { [51\% in 2014] }\end{array}$ & $\begin{array}{l}45.23 \\
(8.06)\end{array}$ & $\begin{array}{c}53.25 \\
(10.66)\end{array}$ & $\begin{array}{c}0.704 \\
(0.136)\end{array}$ & $\begin{array}{c}0.724 \\
(0.149)\end{array}$ & $\begin{array}{c}3.58 \mathrm{SEK} \\
(1.55)\end{array}$ & $\begin{array}{c}3.54 \mathrm{SEK} \\
(1.54)\end{array}$ \\
\hline
\end{tabular}




\section{Figures}

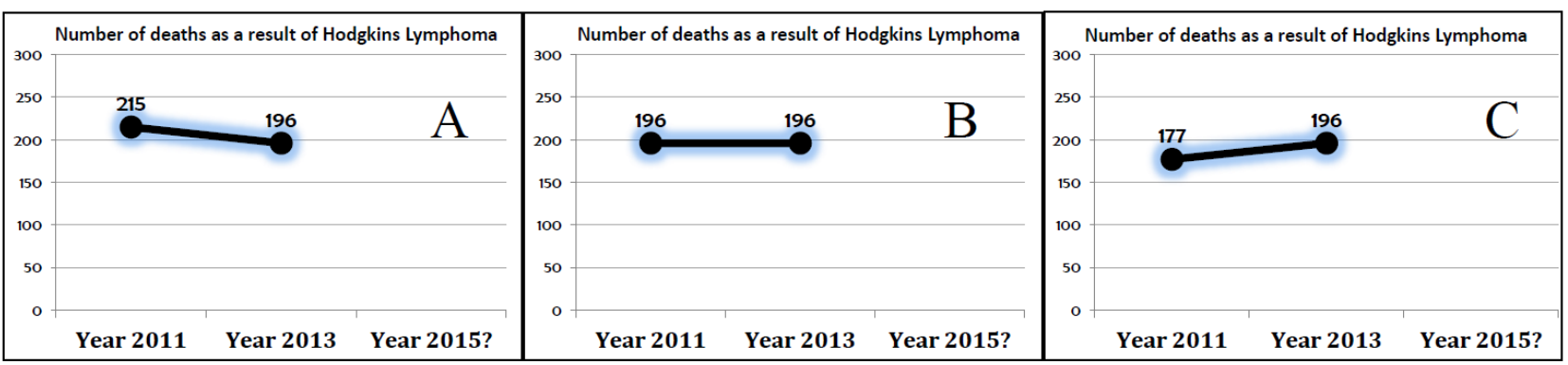

Figure 1. Illustrations of the number of deaths from Hodgkin's Lymphoma in the downward trajectory version (A), the flat trajectory version (B) and the upward trajectory version (C), as shown to participants in Study 1 and 2.
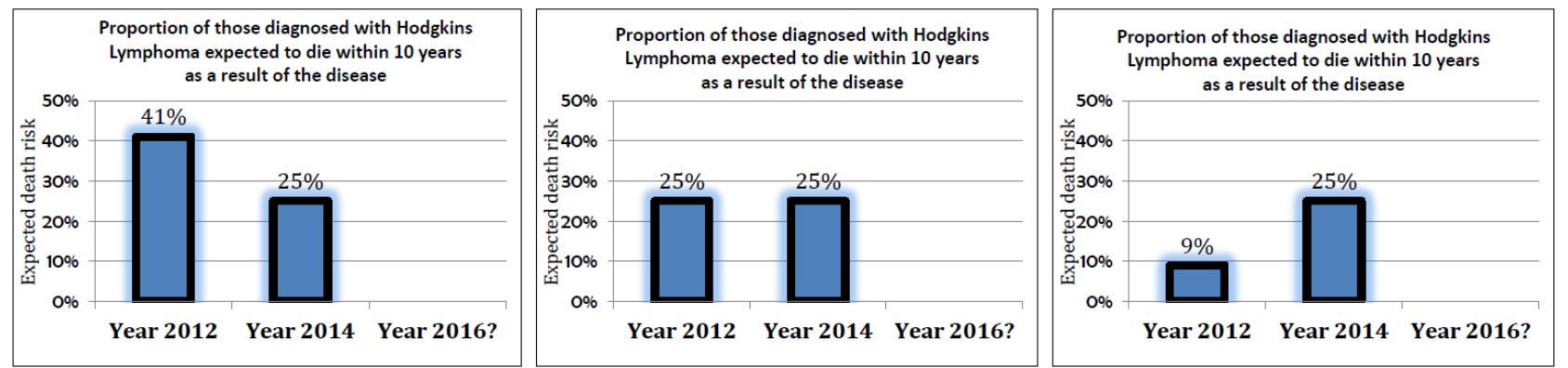

Figure 2. Estimated expected death risk from Hodgkin's Lymphoma in the downward trajectory version $(\mathrm{A})$, the flat trajectory version $(\mathrm{B})$ and the upward trajectory version $(\mathrm{C})$, as shown to participants in Study 3. 


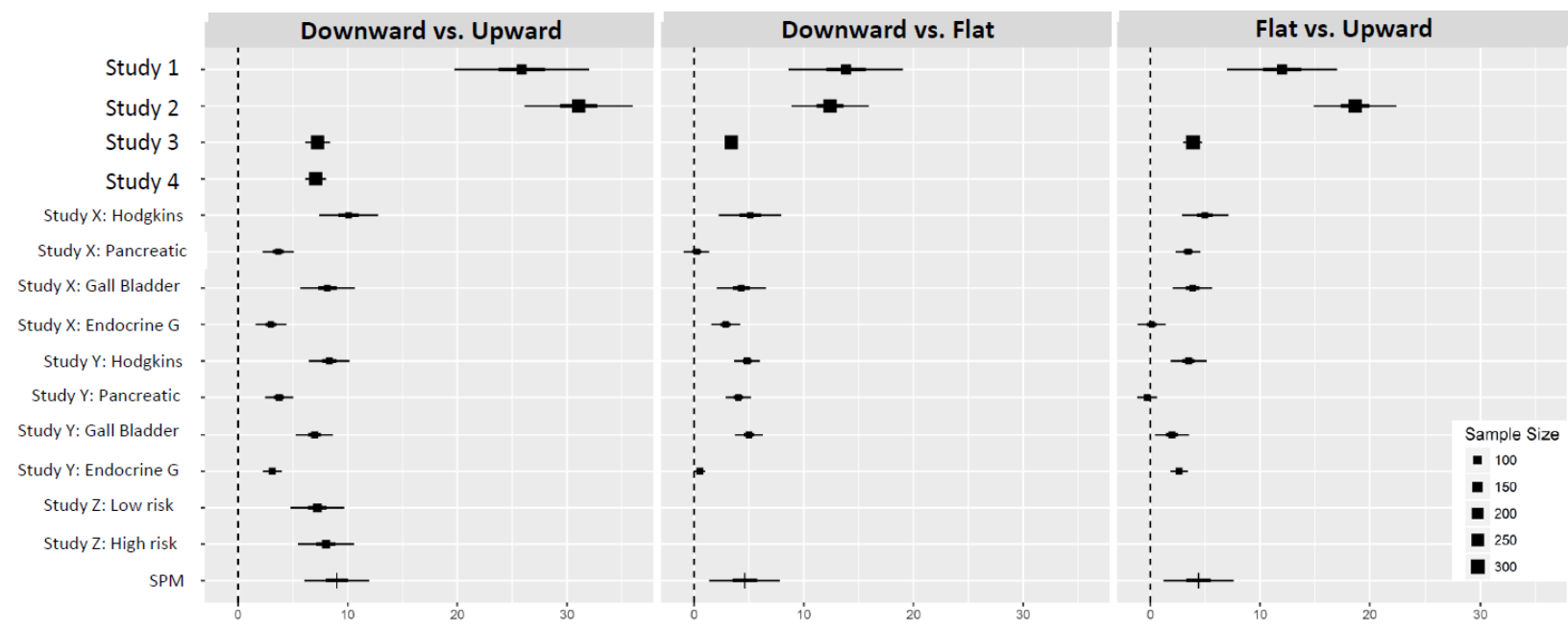

Figure 3. Single paper meta-analysis (SPM) on mortality statistics for the three pairwise contrasts Figure 3 Note. Effect estimates are given by the squares for single-study estimates and the vertical bars for SPM estimates; $50 \%$ and $95 \%$ intervals are given by the thick and thin lines respectively. The average sample size per condition in each study is given by the size of the squares. Mortality statistics was operationalized as number of deaths (Studies 1 and 2), expert-estimated death risk (Studies 3, 4, Y and Z) and survival chance (Study X).

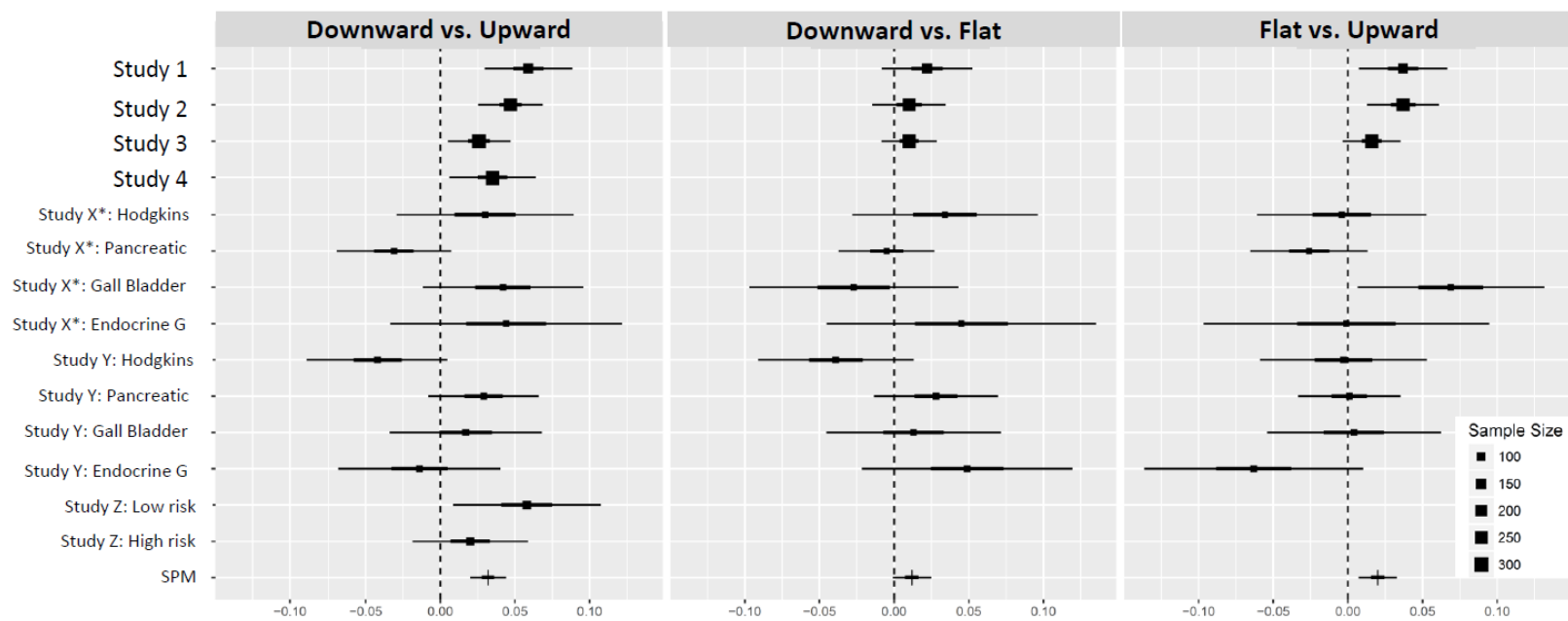

Figure 4. Single paper meta-analysis (SPM) on perceived severity for the three pairwise contrasts Figure 4 Note. Effect estimates are given by the squares for single-study estimates and the vertical bars for SPM estimates; $50 \%$ and $95 \%$ intervals are given by the thick and thin lines respectively. The average sample size per condition in each study is given by the size of the squares. Perceived severity was measured on a Visual Analogue Scale in all studies. Participants obtained a score between 0 and 1 where a higher score indicated higher perceived severity. As Study X manipulated survival chance (not death risk) we have inverted the ratings on downwards and upwards trends in this study. 


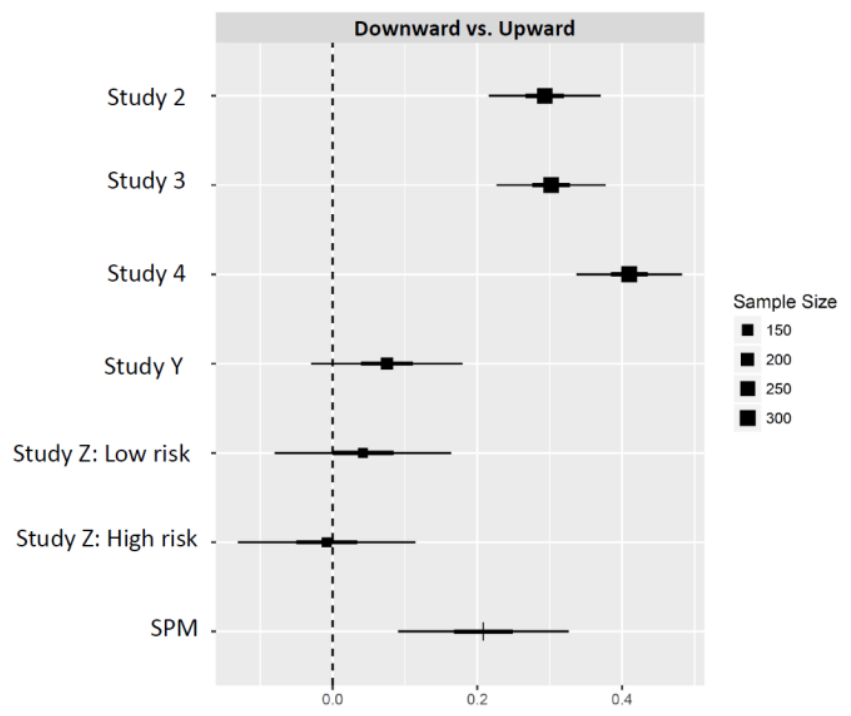

Figure 5. Single paper meta-analysis (SPM) on allocation decision

Figure 5 Note. Effect estimates are given by the squares for single-study estimates and the vertical bars for SPM estimates; $50 \%$ and $95 \%$ intervals are given by the thick and thin lines respectively. The average sample size per condition in each study is given by the size of the squares. Allocation decision was measured by comparing the proportion of participants allocating to a cancer type with downward trajectory with the proportion of participants allocating to a cancer type with upward trajectory (omitting those who donated to a cancer-type with a flat trajectory). 


\section{Appendices}

The following appendices are attached as supplementary material.

Appendix 1. Includes, illustrations of the trajectories used in Studies 1-3 and Studies X \& Y; an example of the purely numerical description used in Study 4 and Study $Z$ and an explanation of the design used in Studies 1-3, X and Y.

Appendix 2. Full presentation of additional Studies X, Y and Z.

Appendix 3. Additional analyses for Studies 1-4 including e.g. demographic, correlations between variables, and the post-hoc justifications.

Appendix 4. Further information about how the single-paper meta-analyses (SPM) was conducted. 


\section{Appendix 1}

Figure A: Illustrations of the trajectories included in Studies 1 and 2.
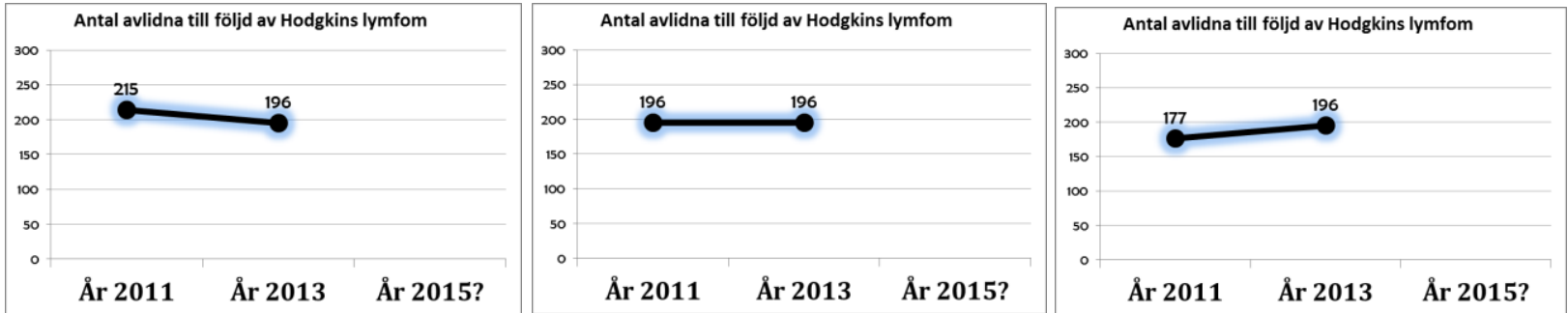

Hodgkin's Lymphoma in the downward, flat and upward trajectory version.

(Header: Number of deaths as a result of Hodgkin's Lymphoma)
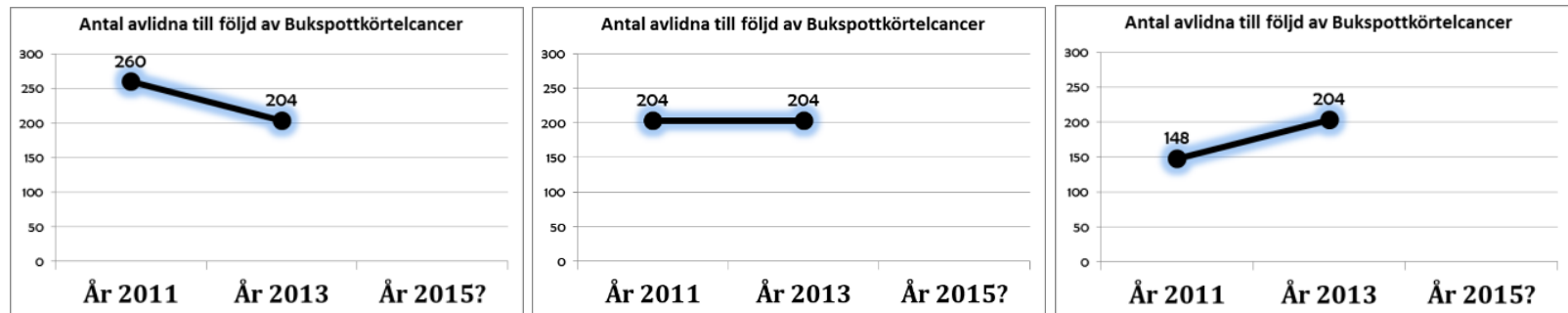

Pancreatic cancer in the downward, flat and upward trajectory version.

(Header: Number of deaths as a result of Pancreatic cancer)
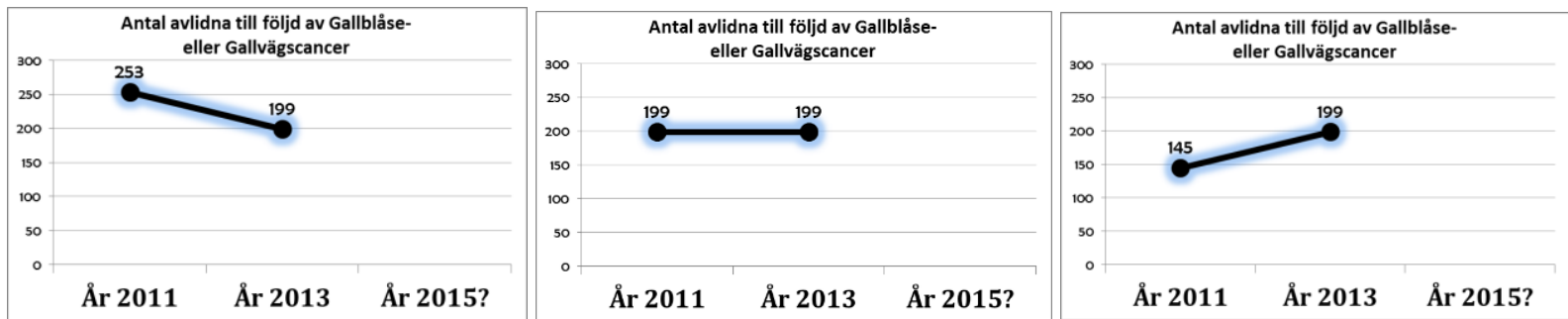

Gall bladder cancer in the downward, flat and upward trajectory version.

(Header: Number of deaths as a result of Gall bladder cancer)
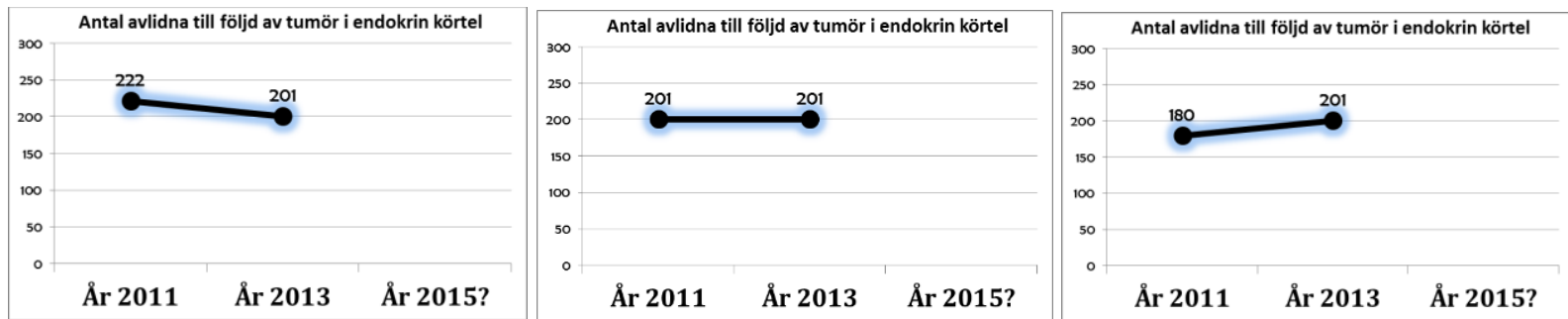

Endocrine gland tumors in the downward, flat and upward trajectory version.

(Header: Number of deaths as a result of Endocrine gland tumors) 
Figure B: Illustrations of the trajectories included in Study 3.
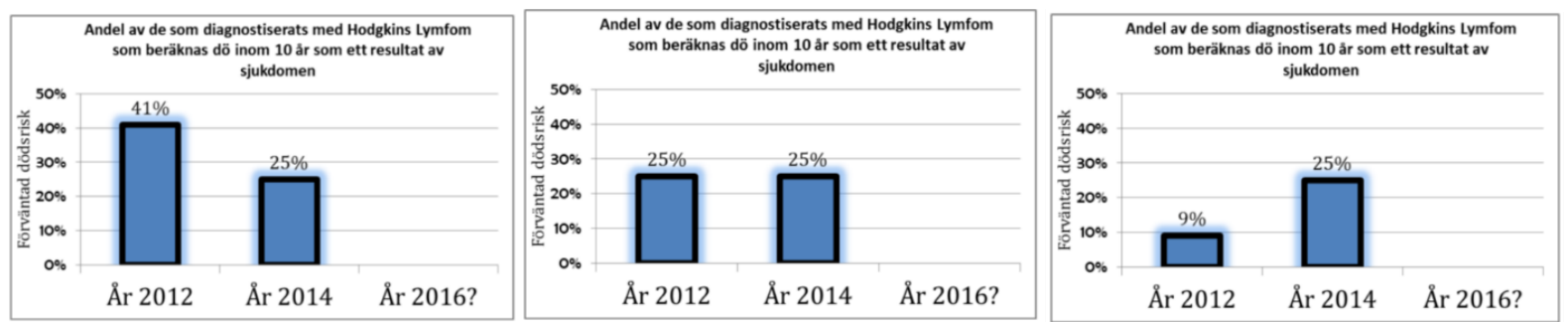

Hodgkin's Lymphoma in the downward, flat and upward trajectory version.

(Header: Proportion of those diagnosed with Hodgkin's Lymphoma that is expected to die within 10 years as a result of the disease)
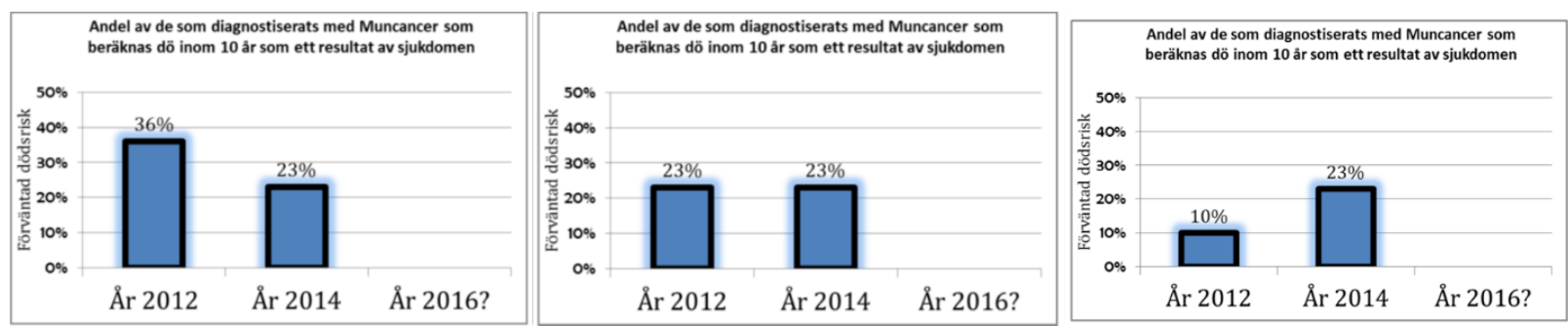

Mouth cancer in the downward, flat and upward trajectory version.

(Header: Proportion of those diagnosed with Mouth cancer that is expected to die within 10 years as a result of the disease)
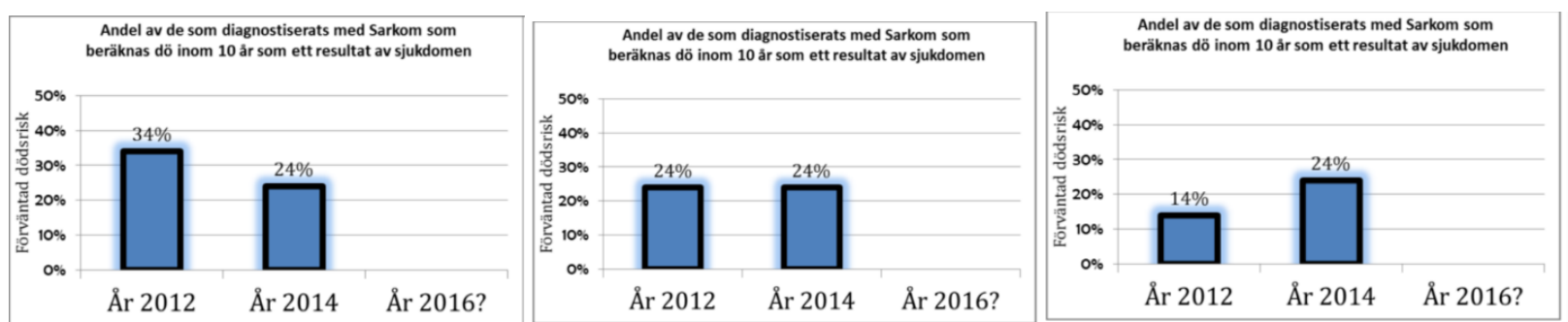

Sarkoma in the downward, flat and upward trajectory version.

(Header: Proportion of those diagnosed with Sarkoma that is expected to die within 10 years as a result of the disease)
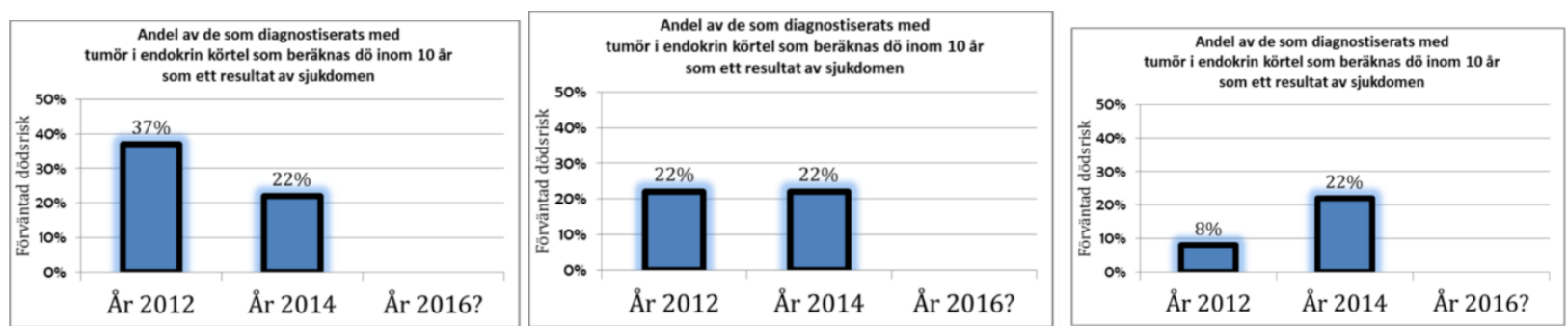

Endocrine gland tumors in the downward, flat and upward trajectory version.

(Header: Proportion of those diagnosed with Endocrine gland tumor that is expected to die within 10 years as a result of the disease) 
Figure C. The 16 versions of the questionnaire with the four cancer types were presented in this order with the following trajectory versions in Studies 1-3 and Studies X and Y. Each questionnaire thus contained one cancer type written in the no trajectory version (= flat trajectory), one or two cancer types written in the upward trajectory version and one or two cancer types written in the downward trajectory versions

\begin{tabular}{|l|l|l|l|l|}
\hline & $\begin{array}{l}\text { Hodgkins } \\
\text { lymphoma }\end{array}$ & $\begin{array}{l}\text { Pancreatic } \\
\text { cancer }\end{array}$ & $\begin{array}{l}\text { Gall bladder } \\
\text { cancer }\end{array}$ & $\begin{array}{l}\text { Tumors in } \\
\text { endocrine glands }\end{array}$ \\
\hline $1 a$ & No & Up & Down & Up \\
\hline $2 a$ & No & Down & Up & Down \\
\hline $3 a$ & Up & No & Down & Up \\
\hline $4 a$ & Down & No & Up & Down \\
\hline $5 a$ & Up & Down & No & Up \\
\hline $6 a$ & Down & Up & No & Down \\
\hline $7 a$ & Up & Down & Up & No \\
\hline $8 a$ & Down & Up & Down & No \\
\hline
\end{tabular}

\begin{tabular}{|l|l|l|l|l|}
\hline & $\begin{array}{l}\text { Tumors in } \\
\text { endocrine glands }\end{array}$ & $\begin{array}{l}\text { Gall bladder } \\
\text { cancer }\end{array}$ & $\begin{array}{l}\text { Pancreatic } \\
\text { cancer }\end{array}$ & $\begin{array}{l}\text { Hodgkins } \\
\text { lymphoma }\end{array}$ \\
\hline $1 \mathrm{~b}$ & Up & Down & Up & No \\
\hline $2 \mathrm{~b}$ & Down & Up & Down & No \\
\hline $3 \mathrm{~b}$ & Up & Down & No & Up \\
\hline 4b & Down & Up & No & Down \\
\hline $5 b$ & Up & No & Down & Up \\
\hline $6 \mathrm{~b}$ & Down & No & Up & Down \\
\hline $7 \mathrm{~b}$ & No & Up & Down & Up \\
\hline $8 \mathrm{~b}$ & No & Down & Up & Down \\
\hline
\end{tabular}


Figure D. Example of the purely numerical description used in Study 4 and Study Z (translated from Swedish)

\section{Hodgkin's Lymphoma}

Hodgkin's Lymphoma is a cancer type that origins from a certain type of white blood cells, B-cell lymphocytes

In the report "Cancer in Numbers" published 2013 by the National Board of Health and Welfare and the Cancer Fund it was estimated that the expected death risk in 2012 for those who had Hodgkin's Lymphoma was around 30\% (i.e. out of 100 sick people, 30 was expected to die within ten years as a direct consequence of the disease).

In the report "Cancer in Numbers" published 2015 by the National Board of Health and Welfare and the Cancer Fund, the estimated expected death risk in 2014 for those who had Hodgkin's Lymphoma had been adjusted downwards to $18 \%$

Within the coming months the 2017 version of "Cancer in Numbers" will be published. What do you think the estimated expected death risk for those who have Hodgkin's Lymphoma is in 2016 ? 
Figure X: Illustrations of the trajectories included in additional Study X.

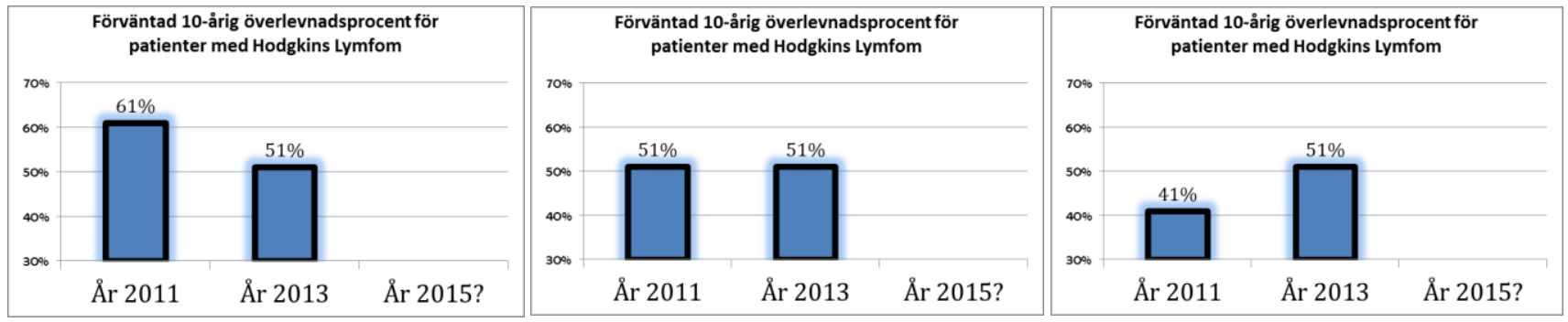

Hodgkin's Lymphoma in the downward, flat and upward trajectory version.

(Header: Expected 10-year survival chance for patients with Hodgkin's Lymphoma)
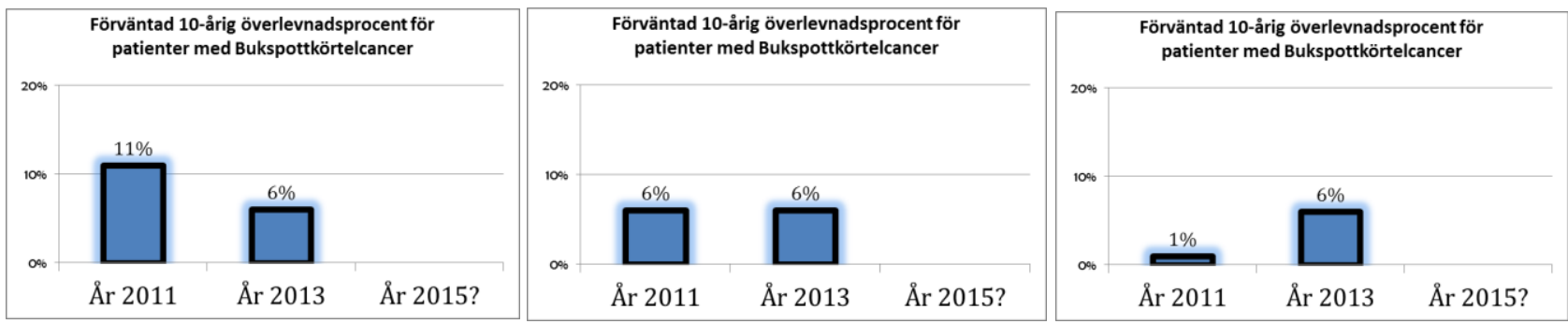

Pancreatic cancer in the downward, flat and upward trajectory version.

(Header: Expected 10-year survival chance for patients with Pancreatic cancer)
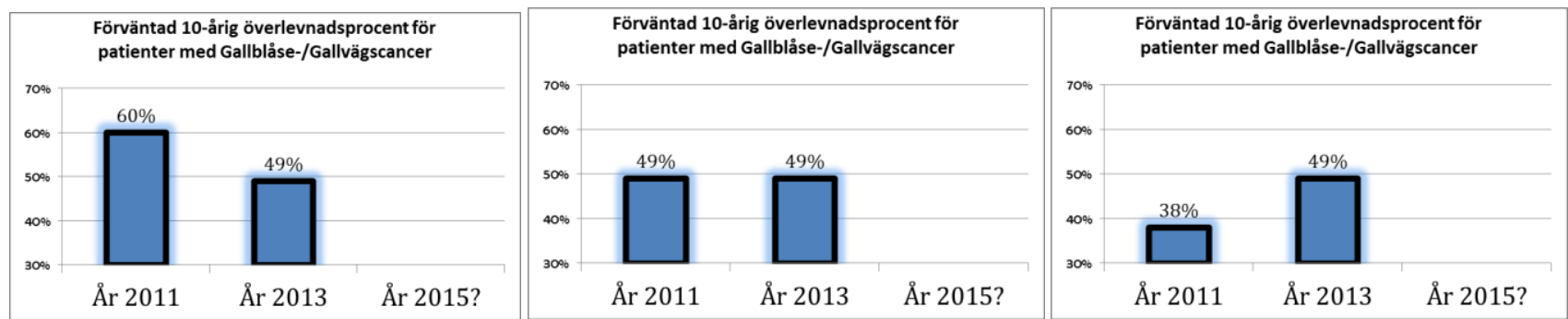

Gall bladder cancer in the downward, flat and upward trajectory version.

(Header: Expected 10-year survival chance for patients with Gall bladder cancer)
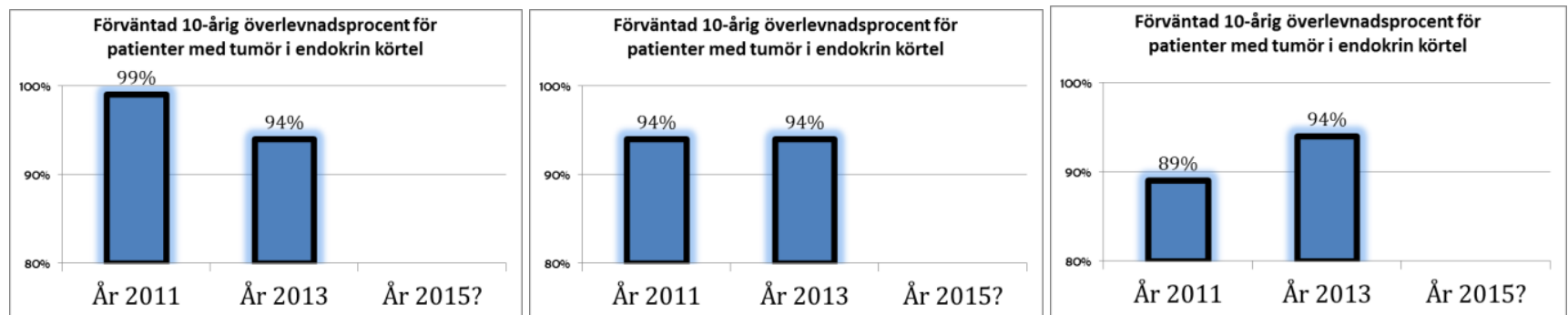

Endocrine gland tumors in the downward, flat and upward trajectory version.

(Header: Expected 10-year survival chance for patients with Endocrine gland tumors) 
Figure Y: Illustrations of the trajectories included in additional Study Y.
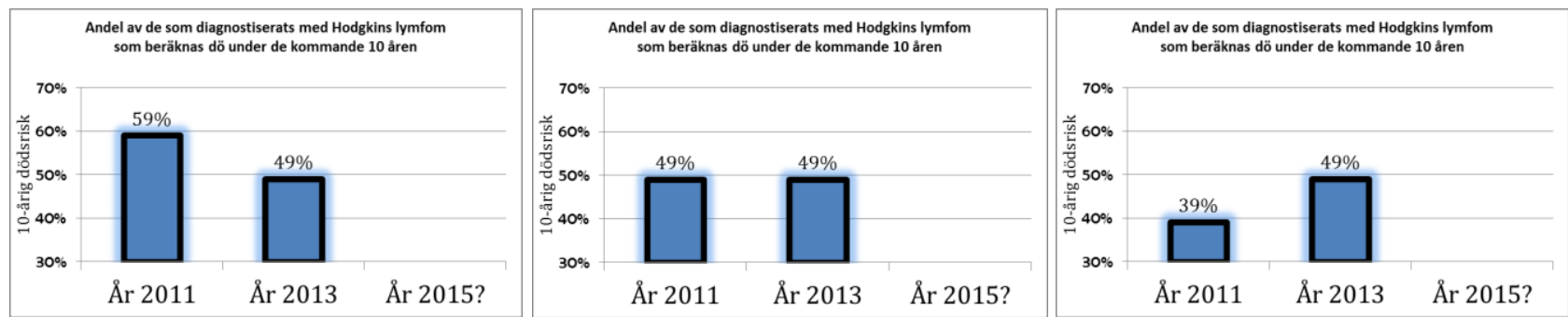

Hodgkin's Lymphoma in the downward, flat and upward trajectory version.

(Header: Proportion of those diagnosed with Hodgkin's Lymphoma that is expected to die during the next 10 years)
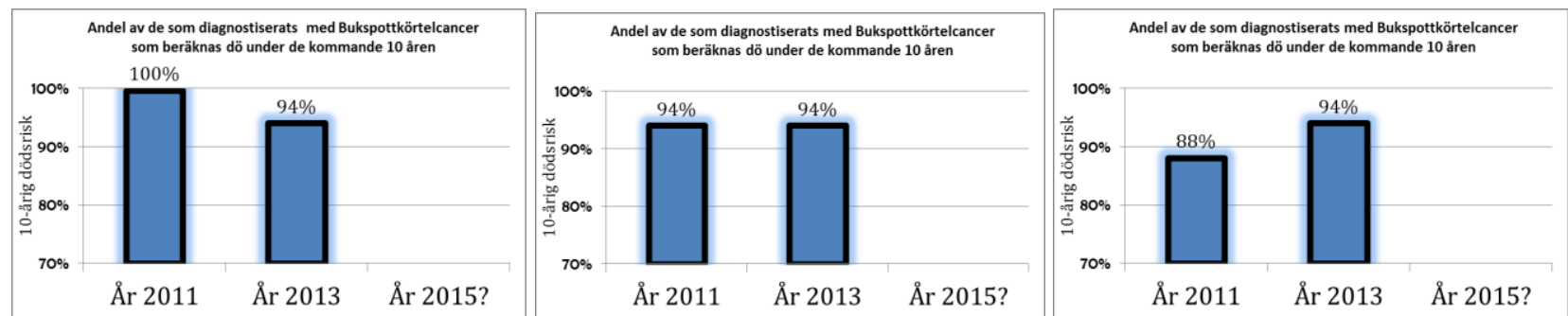

Pancreatic cancer in the downward, flat and upward trajectory version.

(Header: Proportion of those diagnosed with Pancreatic cancer that is expected to die during the next 10 years)
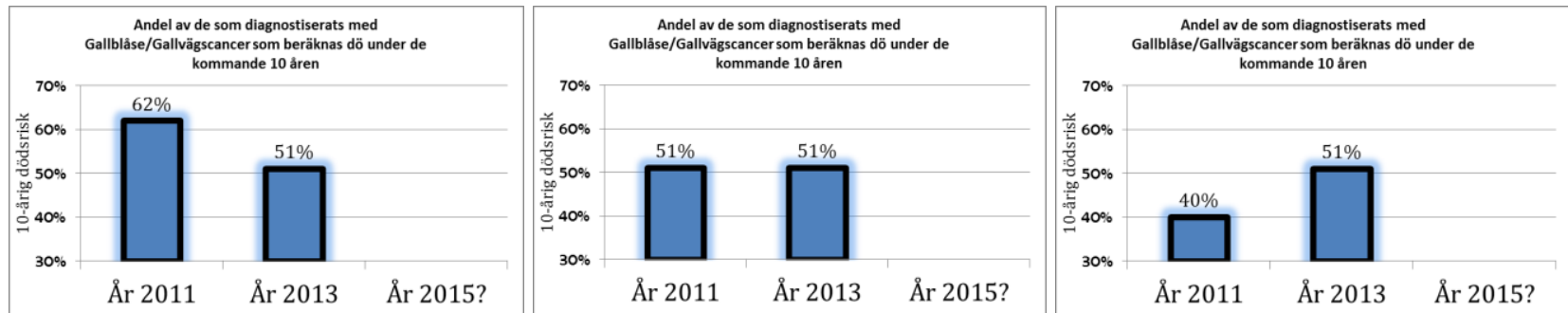

Gall bladder cancer in the downward, flat and upward trajectory version.

(Header: Proportion of those diagnosed with Gall bladder cancer that is expected to die during the next 10 years)
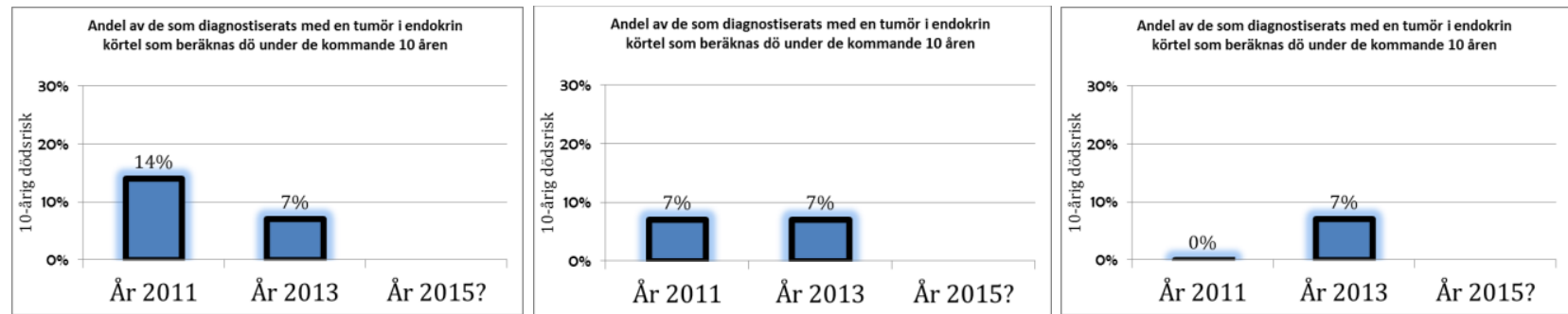

Endocrine gland tumors in the downward, flat and upward trajectory version.

(Header: Proportion of those diagnosed with Endocrine gland tumors that is expected to die during the next 10 years) 


\section{Appendix 2}

\section{Additional Study X}

\section{Participants}

We collected 160 questionnaires (excluding and replacing four non-responders in order to maintain the perfectly balanced design). The final sample included 110 female, 49 male and 1 unclassifiable participant $\left(M_{\mathrm{age}}=29.77, S D=14.66\right)$.

\section{Procedure and Material}

The procedure and material was in large similar to Studies 1-3 but with the following clarifications. First, the numbers presented to the participants illustrated the expert-estimated 10-year chance of survival for a person diagnosed with that cancer type. For example, all participants read that the estimated 10-year survival rate among those diagnosed with Hodgkin's Lymphoma was 51\% in the most recent forecast made in 2013. Participants reading the downward trajectory version read that compared to the forecast made in 2011, the estimated survival rate had been downgraded (61\% chance of survival in 2011, 51\% chance of survival in the 2013 forecast), whereas participants reading the upward trajectory version read that it had been upgraded (41\% chance of survival in the 2011-forecast, $51 \%$ in the 2013-forecast), and participants reading the flat trajectory version read that it had remained unchanged (51\% chance of survival in both the 2011- and 2013-forecasts). Thus, contrary to Studies 1-3 in where an upward trajectory represented something negative, an upward trajectory in this study represented something positive (better chance of survival) whereas a downward trajectory represented something negative (worse chance of survival). Second, importantly and contrary to Studies 1-3, the four different cancer types differed much in their mortality statistics (i.e. estimated chance of survival). Whereas two cancer types had survival chances close to 50\% (Hodgkin's Lymphoma $=51 \%$ and Gall Bladder Cancer $=49 \%$ in 2013), Pancreatic cancer had a very low survival chance $(6 \%)$ and Endocrine gland tumors had a very high survival chance (94\%). The rationale for this was to test whether the different trajectory versions influenced future estimates and perceived severity also close to the end-points. Third, similar to Study 3 , the figures used to illustrate the trajectories were bar diagrams where the y-axis represented the estimated chance of survival. Note that the scale of the y-axis varied in the different cancer types in this study. Fourth, future estimates of chance of survival and perceived severity was rated on the same page (as in Studies 2 and 3). Fifth, no allocation decision was made in this study.

\section{Results}

\section{Estimated chance of survival in 2015}

The trajectories influenced estimates about the future. As the estimated chance of survival differed substantially between the four cancer types, we analyzed them separately rather than aggregately. As can be seen in Table X (left column), the estimated chance of survival in 2015 was significantly higher among those reading the upward trajectory version than among those reading the downward trajectory version for each of the four cancer types (Bonferroni-corrected contrasts). The flat 
trajectory version always rendered estimated survival ratings in between the downward and upward trajectory versions. These results replicate the trend effect when estimating probability forecasts, not only when the probabilities are close to $50 \%$ but also when they are very low or very high.

\section{Perceived severity}

The trajectories did, however, not influence perceived severity. As can be seen in Table X (right column), the perceived severity varied a lot between the different cancer types (as a result of them having very diverse survival chances), but never as result of the different trajectories. If transforming the values into z-scores and then aggregating all the cancer types, the mean perceived severity was $0.085(S D=0.835)$ for the downward trajectory versions, $0.014(S D=0.962)$ for the flat trajectory version and $-0.013(0.843)$ for the upward trajectory version. Although these means are ranked in the predicted order, the differences did not approach significance, $F(2,302)=0.75, p=$ .475 .

\section{Discussion}

Like in Study 3, participants anticipated continued trends and believed that a forecast that had been upgraded once was likely to be upgraded again. This pattern occurred both when the forecast was close to the theoretical mid-point (50\% chance) and when it was close to either of the theoretical end-points (0\% and 100\%). Unlike Study 3 however, the different trajectories did not influence perceived severity of the cancer type. One possible reason is that the numbers in this study illustrated something positive (chance of survival) rather than something negative (number of deaths or risk of dying). Another possible reason is that the chance of survival of the four cancer types differed a lot in this study and that the joint evaluation mode made these differences salient, which in turn diminished the effects of the trajectories. 


\section{THE EFFECT OF TRENDS ON PERCEIVED SEVERITY AND HELP-ALLOCATIONS}

Table X (reproduced)

Estimated chance of survival and perceived severity for the different trajectory versions in additional

Study X.

\begin{tabular}{|c|c|c|c|c|c|c|}
\hline & \multicolumn{3}{|c|}{ Estimated chance of survival in 2015} & \multicolumn{3}{|c|}{ Perceived severity (scale $0-1$ ) } \\
\hline & $\begin{array}{c}\text { Downward } \\
\text { trajectory }\end{array}$ & $\begin{array}{c}\text { Flat } \\
\text { trajectory }\end{array}$ & $\begin{array}{c}\text { Upward } \\
\text { trajectory }\end{array}$ & $\begin{array}{c}\text { Downward } \\
\text { trajectory }\end{array}$ & $\begin{array}{c}\text { Flat } \\
\text { trajectory }\end{array}$ & $\begin{array}{l}\text { Upward } \\
\text { trajectory }\end{array}$ \\
\hline $\begin{array}{l}\text { Hodgkin's Lymphoma } \\
\text { [ } 51 \% \text { chance of survival in } 2013 \text {, } \\
\pm 10 \%]\end{array}$ & $\begin{array}{c}48.05 \%^{\mathrm{a}} \\
(9.18)\end{array}$ & $\begin{array}{c}53.15 \%^{\mathrm{b}} \\
(5.27)\end{array}$ & $\begin{array}{c}58.14 \%^{c} \\
(5.23)\end{array}$ & $\begin{array}{c}0.650^{\mathrm{a}} \\
(0.150)\end{array}$ & $\begin{array}{l}0.654^{\mathrm{a}} \\
(0.136)\end{array}$ & $\begin{array}{l}0.620^{\mathrm{a}} \\
(0.180)\end{array}$ \\
\hline $\begin{array}{l}\text { Pancreatic cancer } \\
{[6 \% \text { chance of survival in } 2013 \text {, }} \\
\pm 5 \% \text { ] }\end{array}$ & $\begin{array}{l}7.07 \%^{\mathrm{a}} \\
(4.02)\end{array}$ & $\begin{array}{c}7.30 \% \%^{\mathrm{a}} \\
(1.77)\end{array}$ & $\begin{array}{c}10.74 \%^{\mathrm{b}} \\
(3.84)\end{array}$ & $\begin{array}{c}0.864^{\mathrm{a}} \\
(0.124)\end{array}$ & $\begin{array}{c}0.890^{\mathrm{a}} \\
(0.076)\end{array}$ & $\begin{array}{c}0.895^{\mathrm{a}} \\
(0.086)\end{array}$ \\
\hline $\begin{array}{l}\text { Gall bladder cancer } \\
{[49 \% \text { chance of survival in } 2013 \text {, }} \\
\pm 11 \%]\end{array}$ & $\begin{array}{c}46.78 \%^{\mathrm{a}} \\
(7.91)\end{array}$ & $\begin{array}{c}51.08 \%^{\mathrm{b}} \\
(3.25)\end{array}$ & $\begin{array}{c}54.93 \%^{\mathrm{c}} \\
(5.87)\end{array}$ & $\begin{array}{c}0.696^{\mathrm{a}} \\
(0.121)\end{array}$ & $\begin{array}{c}0.627^{\mathrm{a}} \\
(0.176)\end{array}$ & $\begin{array}{c}0.654^{\mathrm{a}} \\
(0.174)\end{array}$ \\
\hline $\begin{array}{l}\text { Endocrine gland tumors } \\
\text { [94\% chance of survival in } 2013 \text {, } \\
\pm 5 \%]\end{array}$ & $\begin{array}{c}91.64 \%^{\mathrm{a}} \\
(3.98)\end{array}$ & $\begin{array}{c}94.52 \%^{\mathrm{b}} \\
(2.73)\end{array}$ & $\begin{array}{c}94.65 \%^{\mathrm{b}} \\
(3.76)\end{array}$ & $\begin{array}{l}0.364^{\mathrm{a}} \\
(0.234)\end{array}$ & $\begin{array}{c}0.365^{\mathrm{a}} \\
(0.242)\end{array}$ & $\begin{array}{l}0.320^{\mathrm{a}} \\
(0.198)\end{array}$ \\
\hline
\end{tabular}

Note. Numbers within brackets illustrate the chance of survival estimated by experts in 2013, and the change in chance of survival between 2011 and 2013 in the downward/upward trajectory version). Different subscripts indicate that the mean of the trajectory versions differed significantly $(p<.05$, Bonferronicorrected). 


\section{Additional Study Y}

\section{Participants}

We collected 192 questionnaires but excluded nine because of incomplete responses. Unlike in the previous studies, we did not have the opportunity to replace questionnaires in order to create a perfectly balanced design in this study (nine questionnaire-versions were included 11 times whereas the other seven questionnaire-versions were included 12 times). The final sample included 79 female, 101 male and 3 unclassifiable participants, $M_{\text {age }}=22.73, S D=2.49$.

\section{Procedure and Material}

The procedure and material was similar to Study 3 (estimated death risk + allocation behavior) but with the following differences. First and importantly, whereas all four of the cancer types in Study 3 had expert-estimated death risks in the latest forecast within a narrow range (22\%-25\%), the expert-estimated death risks in the latest forecast were much more diverse in this study and ranged from a very low 7\% (Endocrine gland tumors) to a very high 94\% (Pancreatic cancer). Second, as a consequence of very diverse death risks in the latest forecast, the $y$-axis in the figures were scaled differently for the different cancer types. Third, whereas the donation behavior in Study 3 involved simply choosing which of the four cancer types to support (an allocation decision), the donation behavior in this study was a donation decision. All participants obtained two scratch lottery tickets (each worth 10 SEK) as a sign of gratitude for participation. After responding to all four of the cancer types, participants had the opportunity to donate the buying price of the lottery tickets to the cancer type(s) of their choice. They did so by writing the number of lottery tickets they wanted to donate after each cancer type $(0,1$ or 2$)$ as well as writing the number of lottery tickets they wanted to keep for themselves. The sum of the numbers in all boxes had to be 2 . They put the lottery tickets they wished to donate to any of the cancer types together with the questionnaire in a blank envelope, sealed it and handed it to the experimenter.

\section{Results}

\section{Estimated death risk in 2015}

The trajectories influenced estimates about the future. As the estimated death risk differed substantially between the four cancer types, we analyzed them separately rather than aggregately. As can be seen in Table Y (left column), the estimated death risk in 2015 was significantly higher among those reading the upward trajectory version than among those reading the downward trajectory version for each of the four cancer types. The flat trajectory version rendered estimated death risks in between the downward and upward versions in three of the four cancer types. These results provide further support for the trend effect when estimating probability forecasts.

\section{Perceived severity}

The trajectories did however not influence perceived severity in this study. As can be seen in Table Y (middle column), the perceived severity varied a lot between the different cancer types (as a result of them having very diverse death risks), but never as result of the different trajectories. If transforming the values into z-scores and then aggregating all the cancer types, the mean perceived 
severity was $-0.068(S D=0.990)$ for the downward trajectory versions, $0.070(S D=1.014)$ for the flat trajectory version and $-0.022(0.910)$ for the upward trajectory version, $F(2,362)=1.50, p=$ .224 .

\section{Donation decision}

Six participants did not complete the donation decision and were therefore excluded. 91 of the 177 remaining participants $(51.4 \%)$ kept both lottery tickets. 10 participants kept one and donated one ticket and 76 participants donated both lottery tickets. 161 tickets were donated in total and 1610 SEK were subsequently donated to the Swedish Child Cancer Fund by the experimenters. 56.9\% of the donated lottery tickets were donated to the cancer type with the highest death risk (Pancreatic cancer). 64 of the 161 lottery tickets $(39.8 \%)$ were donated to cancer types with upward trajectory versions, $52(32.3 \%)$ were donated to cancer types with downward trajectory versions and 45 $(28.0 \%)$ were donated to cancer types with flat trajectories. With this design, a random distribution of lottery tickets would be $37.5 \%$ for the downward and upward trajectories and $25 \%$ for the flat trajectory version. A goodness of fit chi-square test indicated that the observed distribution did not significantly differ from a random distribution, $\chi^{2}(2),=1.94, p=.38$. In sum, the trajectory versions did not influence participants' donation decisions.

\section{Discussion}

Like in all the previous studies, participants anticipated continued trends and believed that a forecast that had been upgraded once was likely to be upgraded again. Like in Study X presented above, this occurred both when the forecast was close to the theoretical mid-point (50\% chance) and when it was close to either of the theoretical end-points (0\% and 100\%). Unlike Studies 2 and 3 but similar to Study X, the trajectory versions did not influence perceived severity or donation decisions. As the displayed numbers illustrated something positive (chance of survival) in Study X but something negative (death risk) in Study Y, it seems unlikely that this is the main cause of the absent results on severity in these studies. However, one aspect distinguishes the studies where we did not find the effect from the studies where we did find it. Whereas all the cancer types had similar values during the latest year in Studies 1-3, they had very different values in additional studies $\mathrm{X}$ and $\mathrm{Y}$. Arguably, the trajectories played a large role for severity ratings and allocation decisions when the four cancer types were approximately similar but not when the four cancer types differed. In other words, although trajectories based on only two points of measure can influence both severity ratings and allocation decisions, the effect of trajectories can easily be overshadowed by other more relevant numbers. 


\section{THE EFFECT OF TRENDS ON PERCEIVED SEVERITY AND HELP-ALLOCATIONS}

Table Y (reproduced)

Estimated death risk, perceived severity and number of allocated lottery tickets for the different trajectory versions in additional Study $Y$.

\begin{tabular}{|c|c|c|c|c|c|c|c|c|c|c|}
\hline & \multicolumn{3}{|c|}{$\begin{array}{l}\text { Estimated death risk } \\
\text { in } 2015 \\
\end{array}$} & \multicolumn{3}{|c|}{$\begin{array}{c}\text { Perceived severity } \\
(\text { Scale } 0-1)\end{array}$} & \multicolumn{4}{|c|}{$\begin{array}{c}\text { Donation decision } \\
\text { (number of lottery tickets) }\end{array}$} \\
\hline & $\begin{array}{l}\text { Downward } \\
\text { trajectory }\end{array}$ & $\begin{array}{l}\text { Flat } \\
\text { trajectory }\end{array}$ & $\begin{array}{l}\text { Upward } \\
\text { trajectory }\end{array}$ & $\begin{array}{l}\text { Downward } \\
\text { trajectory }\end{array}$ & $\begin{array}{l}\text { Flat } \\
\text { trajectory }\end{array}$ & $\begin{array}{l}\text { Upward } \\
\text { trajectory }\end{array}$ & $\begin{array}{l}\text { Downward } \\
\text { trajectory }\end{array}$ & $\begin{array}{c}\text { Flat } \\
\text { trajectory }\end{array}$ & $\begin{array}{l}\text { Upward } \\
\text { trajectory }\end{array}$ & $\chi^{2}(2)$ \\
\hline $\begin{array}{l}\text { Hodgkin's } \\
\text { Lymphoma } \\
{[49 \% \text { death }} \\
\text { risk, } \pm 10 \%]\end{array}$ & $\begin{array}{c}43.56 \%^{\mathrm{a}} \\
(4.40)\end{array}$ & $\begin{array}{c}48.39 \%{ }^{\mathrm{b}} \\
(2.02)\end{array}$ & $\begin{array}{c}51.87 \%^{\mathrm{c}} \\
(6.68)\end{array}$ & $\begin{array}{l}0.697^{\mathrm{a}} \\
(0.128)\end{array}$ & $\begin{array}{l}0.658^{\mathrm{a}} \\
(0.151)\end{array}$ & $\begin{array}{l}0.655^{\mathrm{a}} \\
(0.156)\end{array}$ & $\begin{array}{c}10 \\
(45.5 \%)\end{array}$ & $\begin{array}{c}6 \\
(27.3 \%)\end{array}$ & $\begin{array}{c}8 \\
(36.4 \%)\end{array}$ & $\begin{array}{c}0.22 \\
p=.896\end{array}$ \\
\hline $\begin{array}{l}\text { Pancreatic } \\
\text { cancer } \\
{[94 \% \text { death }} \\
\text { risk, } \pm 6 \%]\end{array}$ & $\begin{array}{c}89.06 \%^{\mathrm{a}} \\
(4.48)\end{array}$ & $\begin{array}{c}93.09 \% \mathrm{~b} \\
(1.77)\end{array}$ & $\begin{array}{c}92.81 \%^{\mathrm{b}} \\
(3.12)\end{array}$ & $\begin{array}{l}0.861^{\mathrm{a}} \\
(0.134)\end{array}$ & $\begin{array}{l}0.889^{\mathrm{a}} \\
(0.098)\end{array}$ & $\begin{array}{l}0.890^{\mathrm{a}} \\
(0.087)\end{array}$ & $\begin{array}{c}29 \\
(30.2 \%)\end{array}$ & $\begin{array}{c}29 \\
(30.2 \%)\end{array}$ & $\begin{array}{c}38 \\
(39.9 \%)\end{array}$ & $\begin{array}{c}2.51 \\
p=.285\end{array}$ \\
\hline $\begin{array}{l}\text { Gall bladder } \\
\text { cancer } \\
{[51 \% \text { death }} \\
\text { risk, } \pm 11 \%]\end{array}$ & $\begin{array}{c}44.99 \% \%^{\mathrm{a}} \\
(4.41)\end{array}$ & $\begin{array}{c}49.98 \% \mathrm{~b} \\
(2.73)\end{array}$ & $\begin{array}{c}51.96 \%{ }^{b} \\
(5.72)\end{array}$ & $\begin{array}{l}0.661^{\mathrm{a}} \\
(0.157)\end{array}$ & $\begin{array}{l}0.674^{\mathrm{a}} \\
(0.162)\end{array}$ & $\begin{array}{l}0.678^{a} \\
(0.155)\end{array}$ & $\begin{array}{c}10 \\
(31.3 \%)\end{array}$ & $\begin{array}{c}8 \\
(25 \%)\end{array}$ & $\begin{array}{c}16 \\
(50 \%)\end{array}$ & $\begin{array}{c}1.45 \\
p=.484\end{array}$ \\
\hline $\begin{array}{l}\text { Endocrine } \\
\text { gland tumors } \\
{[7 \% \text { death }} \\
\text { risk, } \pm 7 \%]\end{array}$ & $\begin{array}{c}5.77 \% \%^{\mathrm{a}} \\
(1.82)\end{array}$ & $\begin{array}{c}6.72 \%{ }^{\mathrm{a}} \\
(1.06)\end{array}$ & $\begin{array}{c}8.89 \%^{\mathrm{b}} \\
(3.17)\end{array}$ & $\begin{array}{l}0.318^{a} \\
(0.154)\end{array}$ & $\begin{array}{l}0.367^{\mathrm{a}} \\
(0.215)\end{array}$ & $\begin{array}{l}0.304^{\mathrm{a}} \\
(0.177)\end{array}$ & $\begin{array}{c}3 \\
(42.9 \%)\end{array}$ & $\begin{array}{c}2 \\
(28.6 \%)\end{array}$ & $\begin{array}{c}2 \\
(28.6)\end{array}$ & $\begin{array}{c}0.24 \\
p=.887\end{array}$ \\
\hline
\end{tabular}

Note. Numbers within brackets illustrate the estimated death risk in 2013, and the change in death risk between 2011 and 2013 in the downward/upward trajectory versions. Different subscripts indicate that the mean of the trajectory versions differed significantly $(p<.05)$. A random distribution in the allocation decision would be $37.5 \%$ for the downward and upward trajectory versions and $25 \%$ for the flat trajectory version. 


\section{Additional Study Z}

\section{Participants}

We collected 433 one-paged questionnaires but excluded 11 prior to any analyses because of incomplete responses or because not following instructions. Because this study adopted a betweengroup design it was not necessary to replace the excluded participants. We did not ask participants for any demographic information in this study as we aimed to keep the questionnaire very brief.

\section{Procedure and Material}

In this study participants read about a single cancer type - Hodgkin's Lymphoma. The description was identical to the one used in Study 4 but the mortality statistics was manipulated using a 2 (low/high death risk) $\times 2$ (upward/downward trajectory) factorial design. The expert-estimated death risk at the latest forecast (2014) was $18 \%$ in the low death risk condition and $51 \%$ in the high death risk condition. The difference in death risk between the estimations in 2012 and 2014 was $12 \%$, meaning that the upward trajectory conditions meant $6 \% \rightarrow 18 \%$ or $39 \% \rightarrow 51 \%$ death risk and the downward trajectory conditions meant $30 \% \rightarrow 18 \%$ or $63 \% \rightarrow 51 \%$ in the low and high death risk versions respectively. As in Study 4 no graphical illustration was used in this study. On the same page, participants responded to three questions. 1) The estimated expected death risk in 2016; 2) The perceived severity of Hodgkin's Lymphoma and 3) How much of the endowed sum of 5 SEK that they would like to earmark for preventing and curing Hodgkin's Lymphoma rather than general cancer research. Estimated death risk and perceived severity was assessed like in the previous studies and resource allocations was measured by having the participants circle one number from 0 SEK to 5 SEK indicating the amount the wanted to allocate to Hodgkin's Lymphoma.

\section{Results}

\section{Estimated death risk in 2016}

A $2 \times 2$ between subjects ANOVA with death risk and trajectory as the independent variables and expected estimated death risk in 2016 as the dependent variable showed that there was a large main effect on death risk $F(1,418)=1030.54, p<.001, \eta_{\mathrm{p}}{ }^{2}=.71$. Participants in the high death risk condition naturally expected the death risk in 2016 to be higher than participants in the low death risk condition. More importantly, there was also a main effect on trajectory $F(1,418)=72.07, p<$ $.001, \eta_{\mathrm{p}}{ }^{2}=.15$ meaning that participants in the upward trajectory condition expected the 2016 death risk to be higher than those in the downward trajectory condition. There was no interaction effect $F(1,418)=0.20, p=.658$. These results provide further support for the trend effect when estimating probability forecasts.

\section{Perceived severity}

An identical ANOVA but with perceived severity as the dependent variable showed that there was a main effect on death risk $F(1,413)=58.62, p<.001, \eta_{\mathrm{p}}{ }^{2}=.124$. Participants in the high death risk condition perceived Hodgkin's Lymphoma to be more severe than participants in the low death risk condition did. More importantly, there was also a main effect on trajectory $F(1,413)=5.80, p=$ $.016, \eta_{\mathrm{p}}^{2}=.01$ meaning that participants in the upward trajectory condition perceived Hodgkin's 
Lymphoma as more severe than those in the downward trajectory condition. There was no interaction effect $F(1,413)=1.43, p=.232$. These results show that the trend effect influence severity-ratings also in a pure between-group design.

\section{Allocation decision}

Against expectations, an identical ANOVA but with amount donated as the dependent variable showed that the trajectory-manipulation did not influence allocations $F(1,416)=0.31, p=.578$. Even more remarkably, the death risk manipulation did also not influence allocations, $F(1,416)<$ $0.01, p=.965$, and the interaction effect was also non-significant, $F(1,413)=1.66, p=.408$. To summarize, participants earmarked similar amounts to Hodgkin's lymphoma in all conditions.

\section{Discussion}

The aim of Study $\mathrm{Z}$ was to test the trend effect in a pure between-subject design. Like in Studies 1-4 we replicated the trend effect on expected estimates in the future and on perceived severity suggesting that the findings in the other studies is not an artifact of the specific mixed betweenwithin subject design. However, the expected trend effect did not carry over to the allocation decision in this study. One explanation of this is that the trend effect does not influence allocation decisions when using a pure between-group design. Another explanation is that the allocation decision task used in this study was insensitive not only to different trajectories but insensitive to any manipulation. This later explanation is supported by the non-existent main effect of death risk. Participants earmarked equally much to Hodgkin's Lymphoma when the latest death risk estimate was relatively low (18\%) as when it was relatively high $(51 \%)$.

Table Z (reproduced)

Estimated death risk, perceived severity and amount earmarked to Hodgkin's lymphoma for the different trajectory versions in additional Study Z.

\begin{tabular}{|c|c|c|c|c|c|c|}
\hline & \multicolumn{2}{|c|}{$\begin{array}{l}\text { Estimated death risk of } \\
\text { Hodgkins Lymphoma } \\
\text { in } 2016\end{array}$} & \multicolumn{2}{|c|}{$\begin{array}{c}\text { Perceived severity of } \\
\text { Hodgkins Lymphoma } \\
(0-1)\end{array}$} & \multicolumn{2}{|c|}{$\begin{array}{c}\text { Mean amount } \\
\text { earmarked to } \\
\text { Hodgkins Lymphoma }\end{array}$} \\
\hline & $\begin{array}{l}\text { Downward } \\
\text { trajectory }\end{array}$ & $\begin{array}{l}\text { Upward } \\
\text { trajectory }\end{array}$ & $\begin{array}{c}\text { Downward } \\
\text { trajectory }\end{array}$ & $\begin{array}{l}\text { Upward } \\
\text { trajectory }\end{array}$ & $\begin{array}{c}\text { Downward } \\
\text { trajectory }\end{array}$ & $\begin{array}{l}\text { Upward } \\
\text { trajectory }\end{array}$ \\
\hline $\begin{array}{l}\text { Low death risk } \\
{[18 \% \text { in } 2014]}\end{array}$ & $\begin{array}{l}16.78 \\
(8.16)\end{array}$ & $\begin{array}{l}24.01 \\
(9.78)\end{array}$ & $\begin{array}{c}0.562 \\
(0.180)\end{array}$ & $\begin{array}{c}0.620 \\
(0.185)\end{array}$ & $\begin{array}{c}\text { 3.47 SEK } \\
(1.58)\end{array}$ & $\begin{array}{c}\text { 3.68 SEK } \\
(1.55)\end{array}$ \\
\hline $\begin{array}{l}\text { High death risk } \\
{[51 \% \text { in } 2014]}\end{array}$ & $\begin{array}{l}45.23 \\
(8.06)\end{array}$ & $\begin{array}{c}53.25 \\
(10.66)\end{array}$ & $\begin{array}{c}0.704 \\
(0.136)\end{array}$ & $\begin{array}{c}0.724 \\
(0.149)\end{array}$ & $\begin{array}{c}\text { 3.58 SEK } \\
(1.55)\end{array}$ & $\begin{array}{c}3.54 \text { SEK } \\
(1.54)\end{array}$ \\
\hline
\end{tabular}




\section{Appendix 3}

\section{Study 1}

Participants mean personal experience of cancer on a 11-point Likert scale where $0=$ no experience at all, $10=$ very much personal experience was $5.45(S D=3.29)$. Participants mean political orientation on a 9-point Likert scale where $-4=$ strong leaning towards political left and $+4=$ very strong leaning towards political right was $-0.05(\mathrm{SD}=2.42)$. Participants mean degree of donation routines on a three point scale where $0=$ never donate to organizations preventing cancer, $1=$ occasionally donate, 2 routinely donate was $0.44(\mathrm{SD}=0.53)$.

Table A3-1: Bivariate rank-order correlations for the demographic variables in Study 1

1. Sex $(1=$ male $2=$ female $)$

2. Age

3. Personal experience

4. Donation routines

5. Rightwing political orientation

\begin{tabular}{lllll}
1. & 2. & 3. & 4 & 5 \\
\hline 1 & .07 & .12 & $.38^{* * *}$ & $-.25^{* *}$ \\
& 1 & .06 & .04 & $-.18^{*}$ \\
& & 1 & $.27 * *$ & .03 \\
& & & 1 & .13 \\
& & & & 1
\end{tabular}

Table A3-2: Bivariate rank-order correlations between the demographic variables and estimated number of deaths and perceived severity for the different trajectory versions in Study 1.

\begin{tabular}{|c|c|c|c|c|c|c|c|c|}
\hline & \multicolumn{2}{|c|}{$\begin{array}{c}\text { Downward trajectory } \\
\text { cancer types }\end{array}$} & \multicolumn{2}{|c|}{$\begin{array}{l}\text { Flat trajectory } \\
\text { cancer types }\end{array}$} & \multicolumn{2}{|c|}{$\begin{array}{l}\text { Upward trajectory } \\
\text { cancer types }\end{array}$} & \multicolumn{2}{|c|}{ All aggregated } \\
\hline & $\begin{array}{l}\text { Est. } \\
\text { Deaths }\end{array}$ & Severity & $\begin{array}{l}\text { Est. } \\
\text { Deaths }\end{array}$ & Severity & $\begin{array}{l}\text { Est. } \\
\text { Deaths }\end{array}$ & Severity & $\begin{array}{c}\text { Est } \\
\text { Deaths }\end{array}$ & Severity \\
\hline $\begin{array}{l}1 . \text { Sex } \\
(1=\text { male } \\
2=\text { female })\end{array}$ & -.00 & -.05 & -.04 & .04 & -.03 & -.05 & -.02 & -.03 \\
\hline 2. Age & .06 & -.05 & -.01 & -.07 & -.02 & -.05 & .04 & -.06 \\
\hline $\begin{array}{l}\text { 3. Personal } \\
\text { experience }\end{array}$ & .11 & $.20 *$ & .00 & .10 & .07 & .15 & .13 & $.19 *$ \\
\hline $\begin{array}{l}\text { 4. Donation } \\
\text { routines }\end{array}$ & .08 & .05 & -.06 & .09 & -.05 & -.03 & -.01 & .07 \\
\hline $\begin{array}{l}\text { 5. Rightwing } \\
\text { political } \\
\text { orientation }\end{array}$ & .02 & .05 & -.13 & -.04 & -.14 & -.01 & -.15 & -.02 \\
\hline
\end{tabular}


Table A3-3: Bivariate Pearson correlations between estimated number of deaths and perceived severity for the different trajectory versions of each of the four cancer types in Study 1.

\begin{tabular}{llll}
\hline & $\begin{array}{l}\text { Downward } \\
\text { trajectory }\end{array}$ & $\begin{array}{l}\text { Flat } \\
\text { trajectory }\end{array}$ & $\begin{array}{l}\text { Upward } \\
\text { trajectory }\end{array}$ \\
\cline { 2 - 4 } Hodgkin's Lymphoma & .13 & -.10 & -.03 \\
Pancreatic cancer & .10 & .14 & -.01 \\
Gall bladder cancer & .19 & -.09 & -.01 \\
Endocrine gland tumors & -.02 & -.10 & .01 \\
All cancer-types & $\mathbf{. 1 2}$ & $\mathbf{- . 0 2}$ & $\mathbf{. 0 2}$ \\
aggregated & & & \\
\hline
\end{tabular}




\section{Study 2}

Participants mean political orientation on a 9-point Likert scale where $-4=$ strong leaning towards political left and $+4=$ very strong leaning towards political right was $-0.83(S D=2.25)$. Participants mean degree of donation routines on a three point scale where $0=$ never donate to organizations preventing cancer, $1=$ occasionally donate, $2=$ routinely donate was $0.64(S D=0.61)$.

Table A3-4: Bivariate rank-order correlations for the demographic variables in Study 2

\begin{tabular}{lllll}
\hline & 1. & 2. & 3. & 4 \\
\cline { 2 - 5 } $\begin{array}{l}\text { 1. Sex }(1=\text { male } 2=\text { female }) \\
\text { 2. Age }\end{array}$ & $-.15^{*}$ & $.16^{*}$ & -.10 \\
$\begin{array}{l}\text { 3. Donation routines } \\
\begin{array}{l}\text { 4. Rightwing political } \\
\text { orientation }\end{array}\end{array}$ & 1 & $.26^{* * *}$ & -.02 \\
\hline
\end{tabular}

Table A3-5: Bivariate rank-order correlations between the demographic variables and estimated number of deaths and perceived severity for the different trajectory versions in Study 2.

\begin{tabular}{lcccccccc}
\hline & \multicolumn{2}{c}{$\begin{array}{c}\text { Downward trajectory } \\
\text { cancer types }\end{array}$} & \multicolumn{2}{c}{$\begin{array}{c}\text { Flat trajectory } \\
\text { cancer types }\end{array}$} & \multicolumn{2}{c}{$\begin{array}{c}\text { Upward trajectory } \\
\text { cancer types }\end{array}$} & \multicolumn{2}{c}{ All aggregated } \\
& $\begin{array}{l}\text { Est. } \\
\text { Deaths }\end{array}$ & Severity & $\begin{array}{c}\text { Est. } \\
\text { Deaths }\end{array}$ & Severity & $\begin{array}{c}\text { Est. } \\
\text { Deaths }\end{array}$ & Severity & $\begin{array}{c}\text { Est } \\
\text { Deaths }\end{array}$ & Severity \\
\cline { 2 - 9 } $\begin{array}{l}1 . \text { Sex } \\
(1=\text { male }\end{array}$ & .08 & -.01 & -.04 & .02 & -.11 & -.06 & -.08 & -.04 \\
$\begin{array}{l}2=\text { female }) \\
2 . \text { Age }\end{array}$ & $.24 * * *$ & .06 & $.20 * *$ & .02 & .02 & -.03 & $.16^{* *}$ & .02 \\
$\begin{array}{l}3 . \text { Donation } \\
\text { routines }\end{array}$ & .06 & $.13^{*}$ & -.03 & .06 & .02 & .05 & .01 & .09 \\
$\begin{array}{l}4 . \text { Rightwing } \\
\text { political } \\
\text { orientation }\end{array}$ & -.01 & .05 & .05 & .04 & .11 & .05 & $.13^{*}$ & .03 \\
\hline
\end{tabular}


Table A3-6: Bivariate Pearson correlations between estimated number of deaths and perceived severity for the different trajectory versions of each of the four cancer types in Study 2.

\begin{tabular}{llll}
\hline & $\begin{array}{l}\text { Downward } \\
\text { trajectory }\end{array}$ & $\begin{array}{l}\text { Flat } \\
\text { trajectory }\end{array}$ & $\begin{array}{l}\text { Upward } \\
\text { trajectory }\end{array}$ \\
\cline { 2 - 4 } Hodgkin's Lymphoma & $.27^{* *}$ & .12 & .02 \\
Pancreatic cancer & $.41^{* * *}$ & .17 & $.20^{*}$ \\
Gall bladder cancer & $.29^{* *}$ & .06 & -.07 \\
Endocrine gland tumors & .14 & .12 & .17 \\
\cline { 2 - 4 } $\begin{array}{l}\text { All cancer-types } \\
\text { aggregated }\end{array}$ & $\mathbf{. 3 3 * * *}$ & $.1^{*}$ & $\mathbf{. 1 0}$ \\
\hline
\end{tabular}

\section{Allocation decisions}

There was no sex differences in allocations decisions (i.e. which trajectory version participants donated to; $\left.\chi^{2}(2)=.091, \mathrm{p}=.634\right)$. Also, neither age $(F[2,273]=2.12, p=.12)$ nor political orientation $(F[2,270]=0.48, p=.62)$ had any effect on allocation decisions.

Among those who never donated to cancer organizations 59.2\% donated to upward trajectory cancer types, $17.5 \%$ donated to downward trajectory cancer types and $23.3 \%$ donated to flat trajectory cancer types. Among those who sometimes or routinely donated to cancer organizations $52.2 \%$ donated to upward trajectory cancer types, $31.2 \%$ donated to downward trajectory cancer types and $16.6 \%$ donated to flat trajectory cancer types. This difference was significant, $\chi^{2}(2)=$ $7.25, p=.027$.

\section{Relation between the dependent variables}

We created one variable by computing [estimated number of deaths for upward trajectories estimated number of deaths for downward trajectories] and labeled this "trend effect deaths". A higher score on this variable indicate a greater tendency to believe that trends will continue.

We also created another variable by computing [perceived severity for upward trajectories perceived severity for downward trajectories] and labeled this "trend effect severity". A higher score on this variable indicate a greater tendency to perceive cancer types with upward trajectories as more severe than cancer types with downward trajectories. The bivariate correlation between "trend effect deaths" and "trend effect severity" was $r=.318$.

We then compared participants who allocated money to cancer types with downward /flat /upward trajectories on both "trend effect deaths" and "trend effect severity". 
Table A3-7: Observed trend effect in deaths and perceived severity as a function of which type of trajectory participants donated to in Study 2.

\begin{tabular}{|c|c|c|c|c|}
\hline & $\begin{array}{c}\text { Allocated to } \\
\text { downward } \\
\text { trajectory }\end{array}$ & $\begin{array}{l}\text { Allocated to } \\
\text { flat trajectory }\end{array}$ & $\begin{array}{c}\text { Allocated to } \\
\text { upward } \\
\text { trajectory }\end{array}$ & $\bar{F}$ \\
\hline $\begin{array}{l}\text { Trend effect deaths } \\
\text { (estimated number of } \\
\text { deaths for upward } \\
\text { trajectories - estimated } \\
\text { number of deaths for } \\
\text { downward trajectories) }\end{array}$ & $\begin{array}{c}8.23^{\mathrm{a}} \\
(44.30)\end{array}$ & $\begin{array}{c}30.02^{b} \\
(35.85)\end{array}$ & $\begin{array}{l}42.68^{b} \\
(39.38)\end{array}$ & $\begin{array}{c}F(2,278) \\
=18.36 \\
p<.001\end{array}$ \\
\hline $\begin{array}{l}\text { Trend effect severity } \\
\text { (perceived severity [0-1 } \\
\text { scale] for upward } \\
\text { trajectories minus } \\
\text { perceived severity for } \\
\text { downward trajectories) }\end{array}$ & $\begin{array}{l}-0.084^{\mathrm{a}} \\
(0.172)\end{array}$ & $\begin{array}{c}0.059^{\mathrm{b}} \\
(0.175)\end{array}$ & $\begin{array}{c}0.105^{\mathrm{b}} \\
(0.165)\end{array}$ & $\begin{array}{c}F(2,278) \\
=31.15 \\
p<.001\end{array}$ \\
\hline
\end{tabular}

Note: different subscripts indicate significant differences when conducting Bonferroni-corrected post-hoc pairwise comparisons $(\mathrm{p}<.05)$. 


\section{Post-hoc justifications}

For exploratory reasons, participants rated to what degree seven reasons influenced their decision on a scale ranging including $0=$ did not influence my decision at all, $1=$ influenced my decision to some extent, 2 = influenced my decision to a great extent. The mean importance for the seven included justifications can be seen in the figure below. One-way ANOVAS showed significant main effects on four of the seven justifications (see figure below).

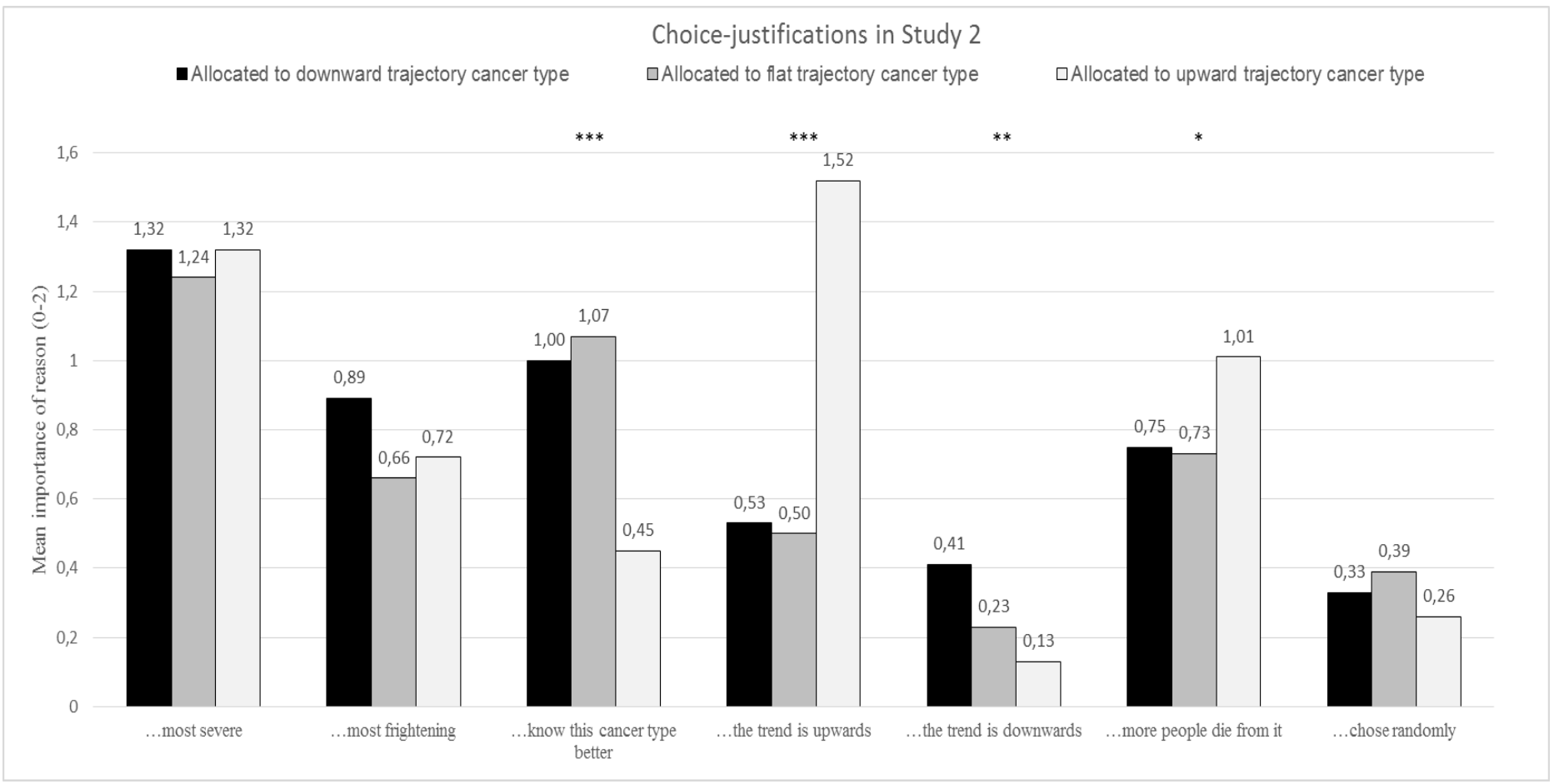




\section{Study 3}

Participants mean political orientation on a 9-point Likert scale where $-4=$ strong leaning towards political left and $+4=$ very strong leaning towards political right was $-0.37(\mathrm{SD}=2.26)$. Participants mean degree of donation routines on a three point scale where $0=$ never donate to organizations preventing cancer, $1=$ occasionally donate, $2=$ routinely donate was $0.56(\mathrm{SD}=0.60)$.

Table A3-8: Bivariate rank-order correlations for the demographic variables in Study 3

\begin{tabular}{lllll}
\hline & 1. & 2. & 3. & 4 \\
\cline { 2 - 5 } $\begin{array}{l}\text { 1. Sex }(1=\text { male } 2=\text { female }) \\
\text { 2. Age }\end{array}$ & 1 & -.08 & $.14^{*}$ & $-.18^{* *}$ \\
$\begin{array}{l}\text { 3. Donation routines } \\
\begin{array}{l}\text { 4. Rightwing political } \\
\text { orientation }\end{array}\end{array}$ & 1 & .11 & .07 \\
\hline
\end{tabular}

Figure A3-9: Bivariate rank-order correlations between the demographic variables and estimated death risk and perceived severity for the different trajectory versions in Study 3.

\begin{tabular}{|c|c|c|c|c|c|c|c|c|}
\hline & \multicolumn{2}{|c|}{$\begin{array}{c}\text { Downward trajectory } \\
\text { cancer types }\end{array}$} & \multicolumn{2}{|c|}{$\begin{array}{l}\text { Flat trajectory } \\
\text { cancer types }\end{array}$} & \multicolumn{2}{|c|}{$\begin{array}{l}\text { Upward trajectory } \\
\text { cancer types }\end{array}$} & \multicolumn{2}{|c|}{ All aggregated } \\
\hline & $\begin{array}{l}\text { Est. } \\
\text { death risk }\end{array}$ & Severity & $\begin{array}{l}\text { Est. } \\
\text { death risk }\end{array}$ & Severity & $\begin{array}{l}\text { Est. } \\
\text { death risk }\end{array}$ & Severity & $\begin{array}{l}\text { Est. } \\
\text { death risk }\end{array}$ & Severity \\
\hline $\begin{array}{l}\text { 1. Sex } \\
(1=\text { male } \\
2=\text { female })\end{array}$ & -.07 & .01 & .05 & .01 & .10 & -.04 & .01 & -.01 \\
\hline 2. Age & $.13^{*}$ & -.05 & .07 & .01 & -.01 & .05 & .08 & .01 \\
\hline $\begin{array}{l}3 \text {. Donation } \\
\text { routines }\end{array}$ & -.10 & .06 & .05 & .10 & $.14 *$ & $.15^{*}$ & -.01 & .10 \\
\hline $\begin{array}{l}\text { 4. Rightwing } \\
\text { political } \\
\text { orientation }\end{array}$ & .01 & .03 & .00 & .09 & -.05 & $.12 *$ & -.02 & .11 \\
\hline
\end{tabular}


Table A3-10: Bivariate Pearson correlations between estimated death risk and perceived severity for the different trajectory versions of each of the four cancer types in Study 3.

\begin{tabular}{llll}
\hline & $\begin{array}{l}\text { Downward } \\
\text { trajectory }\end{array}$ & $\begin{array}{l}\text { Flat } \\
\text { trajectory }\end{array}$ & $\begin{array}{l}\text { Upward } \\
\text { trajectory }\end{array}$ \\
\cline { 2 - 4 } Hodgkin's Lymphoma & $.32^{* *}$ & .07 & $.20^{*}$ \\
Mouth cancer & .12 & .07 & $.34^{* * *}$ \\
Sarcoma & $.36^{* * *}$ & .10 & .17 \\
Endocrine gland tumors & $.25^{* *}$ & .17 & $.25^{* *}$ \\
\cline { 2 - 4 } $\begin{array}{l}\text { All cancer-types } \\
\text { aggregated }\end{array}$ & $\mathbf{. 2 6}$ & .11 & $.25^{* * *}$ \\
\hline
\end{tabular}

\section{Allocation decisions}

There was no sex differences in allocations decisions (i.e. which trajectory version participants donated to; $\left.\chi^{2}(2)=.3 .39, p=.183\right)$. Also, neither age $(F[2,295]=0.37, p=.70)$ nor political orientation $(F[2,293]=2.10, p=.12)$ had any effect on allocation decisions.

Among those who never donated to cancer organizations $57.0 \%$ donated to upward trajectory cancer types, $27.5 \%$ donated to downward trajectory cancer types and $15.4 \%$ donated to flat trajectory cancer types. Among those who sometimes or routinely donated to cancer organizations $53.7 \%$ donated to upward trajectory cancer types, $22.1 \%$ donated to downward trajectory cancer types and $24.2 \%$ donated to flat trajectory cancer types. This difference was not significant, $\chi^{2}(2)=$ $3.88, p=.144$.

\section{Relation between the dependent variables}

As in Study 2, we created one variable by computing [estimated death risk for upward trajectories estimated death risk for downward trajectories] and labeled this "trend effect death risk". A higher score on this variable indicate a greater tendency to believe that trends will continue.

We also created another variable by computing [perceived severity for upward trajectories perceived severity for downward trajectories] and labeled this "trend effect severity". A higher score on this variable indicate a greater tendency to perceive cancer types with upward trajectories as more severe than cancer types with downward trajectories. The bivariate correlation between "trend effect death risk" and "trend effect severity" was $r=.479$.

We then compared participants who allocated money to cancer types with downward /flat /upward trajectories on both "trend effect death risk" and "trend effect severity". 
Table A3-11: Observed trend effect in death risk and perceived severity as a function of which type of trajectory participants donated to in Study 3.

\begin{tabular}{|c|c|c|c|c|}
\hline & $\begin{array}{c}\text { Allocated to } \\
\text { downward } \\
\text { trajectory }\end{array}$ & $\begin{array}{l}\text { Allocated to } \\
\text { flat trajectory }\end{array}$ & $\begin{array}{c}\text { Allocated to } \\
\text { upward } \\
\text { trajectory }\end{array}$ & $\mathrm{F}$ \\
\hline $\begin{array}{l}\text { Trend effect death risk } \\
\text { (estimated death risk } \\
\text { for upward trajectories } \\
\text { - estimated death risk } \\
\text { for downward } \\
\text { trajectories) }\end{array}$ & $\begin{array}{c}2.41^{\mathrm{a}} \\
(9.61)\end{array}$ & $\begin{array}{c}7.17^{b} \\
(8.81)\end{array}$ & $\begin{array}{c}9.53^{\mathrm{b}} \\
(10.27)\end{array}$ & $\begin{array}{l}F(2,304) \\
=13.87 \\
p<.001\end{array}$ \\
\hline $\begin{array}{l}\text { Trend effect severity } \\
\text { (perceived severity [0-1 } \\
\text { scale] for upward } \\
\text { trajectories minus } \\
\text { perceived severity for } \\
\text { downward trajectories) }\end{array}$ & $\begin{array}{l}-0.079^{\mathrm{a}} \\
(0.198)\end{array}$ & $\begin{array}{c}-0.001^{\mathrm{b}} \\
(0.175)\end{array}$ & $\begin{array}{c}0.088^{c} \\
(0.168)\end{array}$ & $\begin{array}{c}F(2,298) \\
=24.07 \\
p<.001\end{array}$ \\
\hline
\end{tabular}

Note: different subscripts indicate significant differences when conducting Bonferroni-corrected post-hoc pairwise comparisons $(\mathrm{p}<.05)$. 


\section{Post-hoc justifications}

Post-hoc justification was assessed as in Study 2 and the mean importance of the seven reasons can be seen in the figure below. Significant main effects are marked.

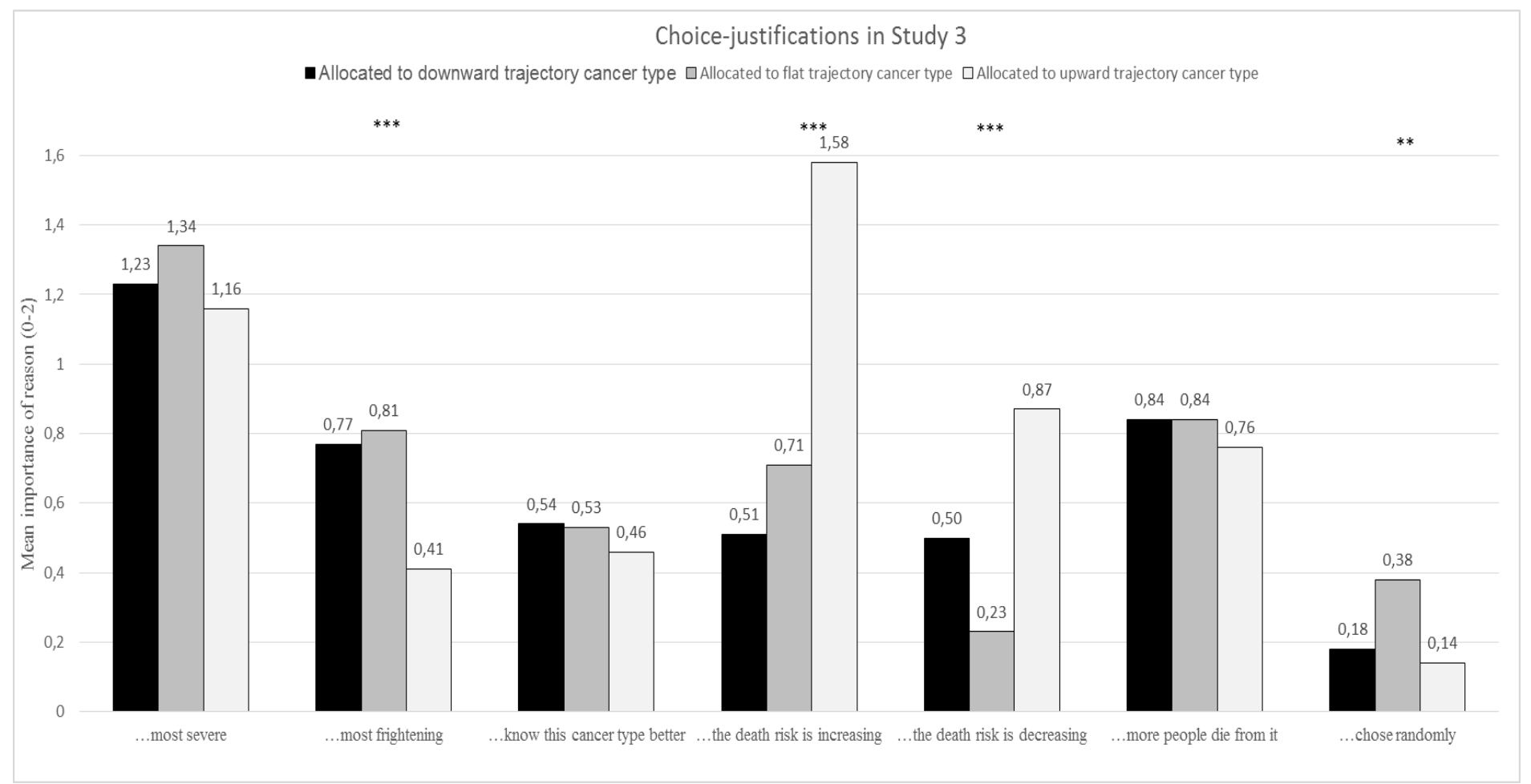




\section{Study 4}

Participants mean political orientation on a 9-point Likert scale where $-4=$ strong leaning towards political left and $+4=$ very strong leaning towards political right was $-0.21(S D=2.34)$. Participants mean degree of donation routines on a three point scale where $0=$ never donate to organizations preventing cancer, $1=$ occasionally donate, $2=$ routinely donate was $0.59(S D=0.62)$.

Table A3-12: Bivariate rank-order correlations for the demographic variables in Study 4

1. Sex $(1=$ male 2 = female $)$

2. Age

3. Donation routines

4. Rightwing political orientation

\begin{tabular}{llll}
1. & 2. & 3. & 4 \\
\hline 1 & .03 & $.17 * * *$ & $-.13^{* *}$ \\
& 1 & $.17 * * *$ & .00 \\
& & 1 & $.15 * * *$ \\
& & & 1
\end{tabular}

Figure A3-13: Bivariate rank-order correlations between the demographic variables, estimated death risk and perceived severity for the different trajectory versions of Hodgkin's Lymphoma (read first) in Study 4.

\begin{tabular}{|c|c|c|c|c|c|c|}
\hline & \multicolumn{2}{|c|}{ Downward trajectory } & \multicolumn{2}{|c|}{ Upward trajectory } & \multicolumn{2}{|c|}{ Both aggregated } \\
\hline & $\begin{array}{l}\text { Est. } \\
\text { Deaths }\end{array}$ & Severity & $\begin{array}{c}\text { Est. } \\
\text { Deaths }\end{array}$ & Severity & $\begin{array}{c}\text { Est } \\
\text { Deaths }\end{array}$ & Severity \\
\hline $\begin{array}{l}\text { 1. Sex } \\
(1=\text { male } \\
2=\text { female })\end{array}$ & .09 & .09 & $.13 *$ & .06 & $.10 *$ & .08 \\
\hline 2. Age & $.14 *$ & .07 & .03 & .06 & .08 & .07 \\
\hline $\begin{array}{l}\text { 3. Donation } \\
\text { routines }\end{array}$ & -.02 & .03 & -.03 & $.13 *$ & -.06 & .08 \\
\hline $\begin{array}{l}\text { 4. Rightwing } \\
\text { political } \\
\text { orientation }\end{array}$ & .01 & $.12 *$ & .01 & .02 & -.02 & .06 \\
\hline
\end{tabular}


Table A3-14: Bivariate Pearson correlations between estimated death risk and perceived severity of the two cancer types in the different conditions in Study 4.

\begin{tabular}{lllll}
\hline & $\begin{array}{l}\text { Hodgkin's: } \\
\text { Downward } \\
\text { trajectory } \\
\text { Endocrine gland } \\
\text { tumors: 17\% } \\
\text { death risk }\end{array}$ & $\begin{array}{l}\text { Hodgkin's: } \\
\text { Downward } \\
\text { trajectory } \\
\text { Endocrine gland } \\
\text { tumors: 19\% } \\
\text { death risk }\end{array}$ & $\begin{array}{l}\text { Hodgkin's: } \\
\text { Upward } \\
\text { trajectory } \\
\text { Endocrine gland } \\
\text { tumors: 17\% } \\
\text { death risk }\end{array}$ & $\begin{array}{l}\text { Hodgkin's: } \\
\text { Upward } \\
\text { trajectory } \\
\text { Endocrine } \\
\text { gland } \\
\text { tumors: 19\% } \\
\text { death risk }\end{array}$ \\
\cline { 2 - 5 } $\begin{array}{l}\text { Hodgkin's } \\
\begin{array}{l}\text { Lymphoma } \\
\text { (rated first) }\end{array}\end{array}$ & .05 & .05 & $.21^{*}$ & $.29 * * *$ \\
$\begin{array}{l}\text { Endocrine gland } \\
\text { tumors } \\
\text { (rated second) }\end{array}$ & -.05 & & & \\
\hline
\end{tabular}

\section{Ratings for endocrine glands tumors}

The 2014 death risk for endocrine gland tumors did influence the expected death risk for the same disease in $2016\left(F[1,575]=93.06, p<.001, \eta_{\mathrm{p}}{ }^{2}=.14\right)$, and to a lesser extent so did the trajectory on Hodgkin's Lymphoma $\left(F[1,575]=5.11, p=.024, \eta_{\mathrm{p}}{ }^{2}=.01\right)$. The interaction effect was also close to significant $\left(F[1,575]=3.79, p=.052, \eta_{\mathrm{p}}{ }^{2}=.01\right)$. Participants unsurprisingly expected the death risk to be higher in 2016 if it had remained stable on $19 \%$ than if it had remained stable on $17 \%$, and especially so if the cancer type they read about before had an upward rather than downward trajectory.

The trajectory on Hodgkin's Lymphoma did marginally influence the perceived severity of Tumors in endocrine glands $\left(F[1,567]=3.21, p=.074, \eta_{\mathrm{p}}^{2}=.01\right)$. Participants reading about Hodgkin's Lymphoma with an upward trajectory perceived tumors in endocrine glands to be slightly less severe $(0.536, S D=0.175)$ than those who read about Hodgkin's Lymphoma with a downward trajectory $(0.562, S D=0.170)$. Neither the main effect of death risk for tumors in endocrine glands $(F[1,567]=2.00, p=.158)$ nor the interaction effect $\left(F[1,567]=1.72, p=.190, \eta_{\mathrm{p}}{ }^{2}=.003\right)$ were significant. 
Table A3-15: Estimated death risk and perceived severity of Endocrine gland tumors (read and responded to after Hodgkin's Lymphoma) for the different trajectory versions in Study 4

\begin{tabular}{|c|c|c|c|c|}
\hline & \multicolumn{2}{|c|}{$\begin{array}{l}\text { Estimated death risk } \\
\text { of Endocrine gland tumors } \\
\text { in } 2016\end{array}$} & \multicolumn{2}{|c|}{$\begin{array}{c}\text { Perceived severity of Endocrine } \\
\text { gland tumors } \\
(0-1)\end{array}$} \\
\hline & $\begin{array}{c}\text { Downward } \\
\text { trajectory in } \\
\text { Hodgkin's } \\
(30 \% \rightarrow 18 \%)\end{array}$ & $\begin{array}{c}\text { Upward } \\
\text { trajectory in } \\
\text { Hodgkin's } \\
(6 \% \rightarrow 18 \%)\end{array}$ & $\begin{array}{c}\text { Downward } \\
\text { trajectory in } \\
\text { Hodgkin's } \\
(30 \% \rightarrow 18 \%)\end{array}$ & $\begin{array}{c}\text { Upward } \\
\text { trajectory in } \\
\text { Hodgkin's } \\
(6 \% \rightarrow 18 \%)\end{array}$ \\
\hline $\begin{array}{l}\text { Lower death risk of } \\
\text { Endocrine gland } \\
\text { tumors }[17 \% \rightarrow 17 \%]\end{array}$ & $16.72(2.17)$ & $16.78(2.28)$ & $0.542(0.168)$ & $0.535(0.171)$ \\
\hline $\begin{array}{l}\text { Higher death risk of } \\
\text { Endocrine gland } \\
\text { tumors }[19 \% \rightarrow 19 \%]\end{array}$ & $18.12(2.32)$ & $18.89(2.00)$ & $0.582(0.171)$ & $0.537(0.179)$ \\
\hline
\end{tabular}




\section{Appendix 4}

Information about the single-paper meta-analyses (SPM)

We read McShane, B.B. and Böckenholt, U. (2017), 'Single Paper Meta-analysis: Benefits for Study Summary, Theory-testing, and Replicability.' Journal of Consumer Research , 43(6), 1048-1063, and used their website https://blakemcshane.shinyapps.io/spmeta/ to conduct the meta-analyses. The values that went into the analyses are presented below. 
THE EFFECT OF TRENDS ON PERCEIVED SEVERITY AND HELP-ALLOCATIONS

\section{Estimated mortality statistics}

(Mortality statistics was operationalized as number of deaths (Studies 1 and 2), expert-estimated death risk (Studies 3, 4, Y and Z) and survival chance (Study X).

Number of experiments: 14

Number of experimental factors: 1

All experiments are between subjects: NO

Experimental factor 1: Downward, Flat, Upward

Means or Proportions (y): 183.32197 .16209 .18188 .88201 .27219 .9419 .7323 .1126 .9914 .32 . 21.40 48.05 53.1558 .147 .077 .3010 .7446 .7851 .0854 .9391 .6494 .5294 .6543 .5648 .3951 .8789 .0693 .0992 .81 44.9949 .9851 .965 .776 .278 .8916 .78 . 24.0145 .23 . 53.25

Standard Deviations (sd): 25.6120 .7727 .8827 .7718 .4730 .965 .413 .207 .354 .87 . 6.549 .185 .275 .234 .02 1.773 .847 .913 .255 .873 .982 .733 .764 .402 .026 .684 .481 .773 .124 .412 .735 .721 .821 .063 .178 .16 . 9.788 .06 . 10.66

Sample Sizes (n): 160160160288288288320320320290.29060406060406060406060406072 4872724872724872724872105.105105 .105

Within subjects group IDs (wi): 1112223334.56789101112131415161718192021222324 252627282930.3132 .33

Within subjects covariances (cov): -18.61 -67.56 83.7 97.76-44.77 117.49 4.21 -11.06 0.72

Number of experimental contrasts: $3(-101 ;-1 \quad 10 ; 0-11)$ 


\section{Perceived severity}

Perceived severity was measured on a Visual Analogue Scale in all studies. Participants obtained a score between 0 and 1 where a higher score indicated higher perceived severity. As Study X manipulated survival chance (not death risk) we have inverted the ratings on downwards and upwards trends in this study.

Number of experiments: 14

Number of experimental factors: 1

All experiments are between subjects: NO

Experimental factor 1: Downward, Flat, Upward

Means or Proportions (y): 0.6240 .6460 .6830 .5780 .5880 .6250 .5590 .5690 .5850 .528 0.563 0.620.654

0.650 .8950 .890 .8640 .6540 .6270 .6960 .320 .3650 .3640 .6970 .6580 .6550 .8610 .8890 .890 .6610 .674

0.6780 .3180 .3670 .3040 .562 . $0.6200 .704 \cdot 0.724$

Standard Deviations (sd): 0.1990 .1960 .1620 .1880 .2090 .1770 .1920 .1990 .1940 .178 . 0.1760 .180 .136

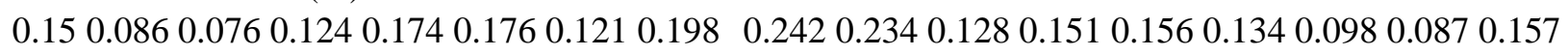

$0.1620 .1550 .1540 .2150 .1770 .18 \cdot 0.1850 .136 \cdot 0.149$

Sample Sizes (n): 160160160288288288320320320290.29060406060406060406060406072 4872724872724872724872105.105105 .105

Within subjects group IDs (wi): 1112223334.56789101112131415161718192021222324 252627282930.3132 .33

Within subjects covariances (cov): 0.020 .0150 .0140 .0170 .0160 .0160 .0240 .0190 .023

Number of experimental contrasts: $3(-101 ;-110 ; 0-11)$ 


\section{Allocation decision}

Allocation decision was measured by comparing the proportion of participants allocating to a cancer type with downward trajectory with the proportion of participants allocating to a cancer type with upward trajectory (omitting those who donated to a cancer-type with a flat trajectory).

Number of experiments: 6

Number of experimental factors: 1

All experiments are between subjects: NO

Experimental factor 1: Downward, Upward

Means or Proportions (y): 0.2580 .5510 .250 .5520 .3270 .7370 .3230 .3980 .6940 .7360 .7160 .708

Standard Deviations (sd): [Blank]

Sample Sizes (n): 283283294294300300161161105105105105

Within subjects group IDs (wi): 112234556789

Number of experimental contrasts: $1\left(\begin{array}{ll}-1 & 1\end{array}\right)$ 